\title{
Spatial distributions of electromagnetic field variations and injection regions during the 20 November 2007 sawtooth event
}

\author{
S. Kasahara ${ }^{1}$, Y. Miyashita ${ }^{2}$, T. Takada ${ }^{1}$, M. Fujimoto ${ }^{1}$, V. Angelopoulos ${ }^{3}$, H. U. Frey ${ }^{3}$, J. Bonnell ${ }^{4}$, J. P. McFadden ${ }^{4}$, \\ D. Larson ${ }^{4}$, K. H. Glassmeier ${ }^{5}$, H. U. Auster ${ }^{5}$, W. Magnes ${ }^{6}$, and I. Mann \\ ${ }^{1}$ Institute of Space and Astronautical Science, JAXA, Kanagawa, Japan \\ ${ }^{2}$ Solar-Terrestrial Environment Laboratory, Nagoya University, Aichi, Japan \\ ${ }^{3}$ University of California, Los Angeles, CA, USA \\ ${ }^{4}$ University of California, Berkeley, CA, USA \\ ${ }^{5}$ Technical University of Braunschweig, Braunschweig, Germany \\ ${ }^{6}$ Space Research Institute, Austrian Academy of Sciences, Graz, Austria \\ ${ }^{7}$ University of Alberta, Edmonton, Alberta, Canada
}

Received: 9 June 2008 - Revised: 27 July 2009 - Accepted: 30 September 2009 - Published: 9 October 2009

\begin{abstract}
We report multi-spacecraft and ground-based observations of a "sawtooth" event on 20 November 2007. For this event, data from three THEMIS, two GOES, and four LANL spacecraft are available as well as those from extensively distributed ground magnetometers and all-sky imagers. In the present paper we focus on the spatial extents of the electromagnetic and particle signatures of the first "tooth". In this event, auroral images and ground magnetic bays showed two activations: a pseudo onset and a major onset (we use the term pseudo onset since the former auroral brightening did not significantly expand poleward). Ground magnetic bay observations indicate that the substorm current wedge (SCW) developed after the major onset in an azimuthally wide region of $\sim 14-3 \mathrm{~h}$ MLT. Similarly, broad magnetic bay distribution was observed also for the pseudo onset prior to the major onset. Furthermore, around the pseudo onset, magnetic dipolarisations were observed from 0.5 to $5 \mathrm{~h}$ MLT. These observations illustrate that, during sawtooth events, activities following not only the major onset but also the pseudo onset can extend more widely than those during usual substorms. Remarkable electromagnetic field fluctuations embedded in the dipolarisation trend were seen at 0.5 and $2.5 \mathrm{~h}$ MLT. In particular, comprehensive plasma and field data from THEMIS showed the presence of a long-excited weak magnetosonic wave and an impulsive large-amplitude Alfvén wave with an earthward Poynting flux at around the eastward edge of the SCW; the latter was sufficiently strong for powering aurora $\left(140 \mathrm{~mW} / \mathrm{m}^{2}\right.$
\end{abstract}

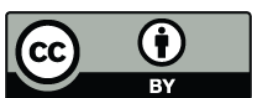

Correspondence to: S. Kasahara (kshr@stp.isas.jaxa.jp) when mapped to the ionosphere). These two activations of the electromagnetic wave were identified, corresponding to the pseudo onset and the major onset. On the other hand, the dipolarisation at geosynchronous $0 \mathrm{~h}$ MLT was observed only after the major onset, despite its closer location to the centre of the auroral activity in terms of the MLT; this indicates that the inner radial limit of the dipolarisation region at the pseudo onset was tailward of geosynchronous altitude at $0 \mathrm{~h}$ MLT. The outer radial limit of the electron injection region was also found at $\sim 10 R_{E}$ by conjunction measurements with THEMIS satellites. These radial distributions are not significantly different to those expected for usual substorms.

Keywords. Magnetospheric physics (Electric fields; Energetic particles, trapped; Storms and substorms)

\section{Introduction}

Quasiperiodic oscillations of energetic particle flux (EPF), the so-called sawtooth event, were identified more than ten years ago (e.g., Borovsky et al., 1993; Belian et al., 1995). The recurrent EPF variations have a periodicity of 2-3 h and can last more than five cycles (Huang et al., 2003a; Henderson et al., 2006b). Each "tooth" consists of a sharp flux increase and a subsequent gradual decrease near the geosynchronous region, associated with magnetic dipolarisation.

Although the sudden EPF increase can also be seen during isolated substorms, the most significant phenomenological difference between sawtooth events and isolated substorms is that the former has larger longitudinal extents in EPF dispersionless enhancement (Henderson et al., 2006a).

Published by Copernicus Publications on behalf of the European Geosciences Union. 
Furthermore, it is well known that the azimuthally broader distributions are also seen for magnetic dipolarisation (Cai et al., 2006) and magnetic bays on the ground (Kitamura et al., 2005). Based on a statistical study with GOES data, Cai et al. (2006) argued that the dipolarisation is seen from $16 \mathrm{~h}$ to $4 \mathrm{~h}$ MLT, and the initiation is in the sector between $22 \mathrm{~h}$ and $0 \mathrm{~h}$ MLT. Kitamura et al. (2005) deduced the substorm current wedge (SCW) of a full width (at full maximum) of $\sim 12 \mathrm{~h}$ in MLT from ground-based magnetometer data. In their events, the centres of the SCWs were seen between $18 \mathrm{~h}$ and $3 \mathrm{~h}$ MLT. The above results are more or less consistent in a sense that these substorm signatures are seen over a broad azimuthal range, although it is also known that their appearances are not globally simultaneous (see Henderson et al., 2006a, b).

Whereas the global scale, conspicuous morphologies are well established, weak activities and short time-scale signatures have been very often ignored due to the long timescale nature of sawtooth events. For instance, in the previous studies, pseudobreakups (pseudo substorm onsets) during sawtooth events have not been focused on. It is generally thought that pseudobreakups are short-lived, weak, and small in the scale size (cf. Ohtani et al., 1993; Nakamura et al., 1994). On the other hand, under a definition that pseudobreakups are substorm-like activities that are not associated with a significant $\left(>2^{\circ}\right)$ poleward expansion, Aikio et al. (1999) reported that pseudobreakups did not differ from usual substorm breakups in the longitudinal extent. This result casts a question of whether pseudobreakups extend over the wider-than-usual range during sawtooth events. Such an issue, however, has not been examined due to the inconspicuousness of the weak activities during sawtooth events.

Another issue that has not been extensively addressed is low-frequency (e.g., Pi2 range) disturbances of the electromagnetic field and plasma in the near-Earth plasma sheet around geosynchronous orbit. Although ground Pi2 waves have been observed over a substantial extent in the azimuthal direction including high latitudes, (e.g., Henderson et al., 2006b), the corresponding oscillations in the plasma sheet have not been examined around geosynchronous altitude; the absence is caused by the lack of electric field instruments and the sufficient time resolution of plasma measurements.

In the present paper, we report the multi-spacecraft observations around geosynchronous orbit, as well as the ground observations, focusing on the first "tooth" of a sawtooth event on 20 November 2007. The fortuitous spacecraft configuration provides the spatial extents of the magnetic field variations and energetic particle injection regions. In addition to the LANL and GOES data, THEMIS at postmidnight geosynchronous altitude provides a full set of particle and field data, which enables detailed analyses of the electromagnetic field variations associated with the global disturbance.

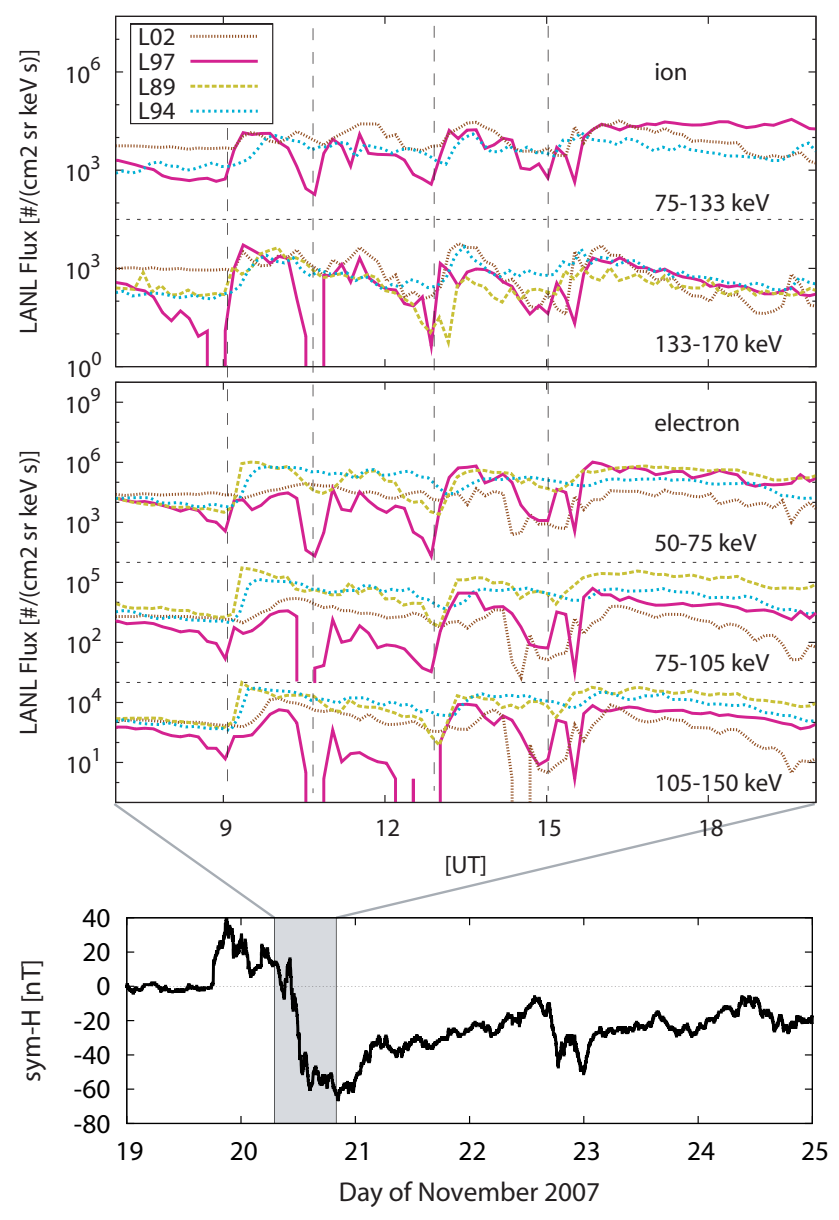

Fig. 1. Sawtooth-like variations of energetic ions (top two panels) and electrons (middle three panels). The flux values are plotted every $10 \mathrm{~min}$. Vertical broken lines are drawn for visual aid. The Sym- $H$ index is also displayed at the bottom.

\section{Observations}

\subsection{Instrumentation}

THEMIS is a constellation of five satellites (Angelopoulos, 2008). Each satellite has an equatorial orbit and observes the inner magnetospheric region at every pass. In the present paper, we utilised data obtained by THEMIS-C (THC), -D (THD), and -E (THE). THC was the only THEMIS satellite that was located near the nightside geosynchronous region during the event, while THD and THE were in the dawn sector at a radial distance of $\sim 10 R_{E}$. We used low-energy particle data obtained by the Electrostatic Analyzer (ESA, McFadden et al., 2008) and energetic particle flux data acquired by the Solid State Telescope (SST). The electric field and magnetic field data are obtained by the Electric Field Instrument (EFI, Bonnell et al., 2008) and the Fluxgate Magnetometer (FGM, Auster et al., 2008), respectively. 


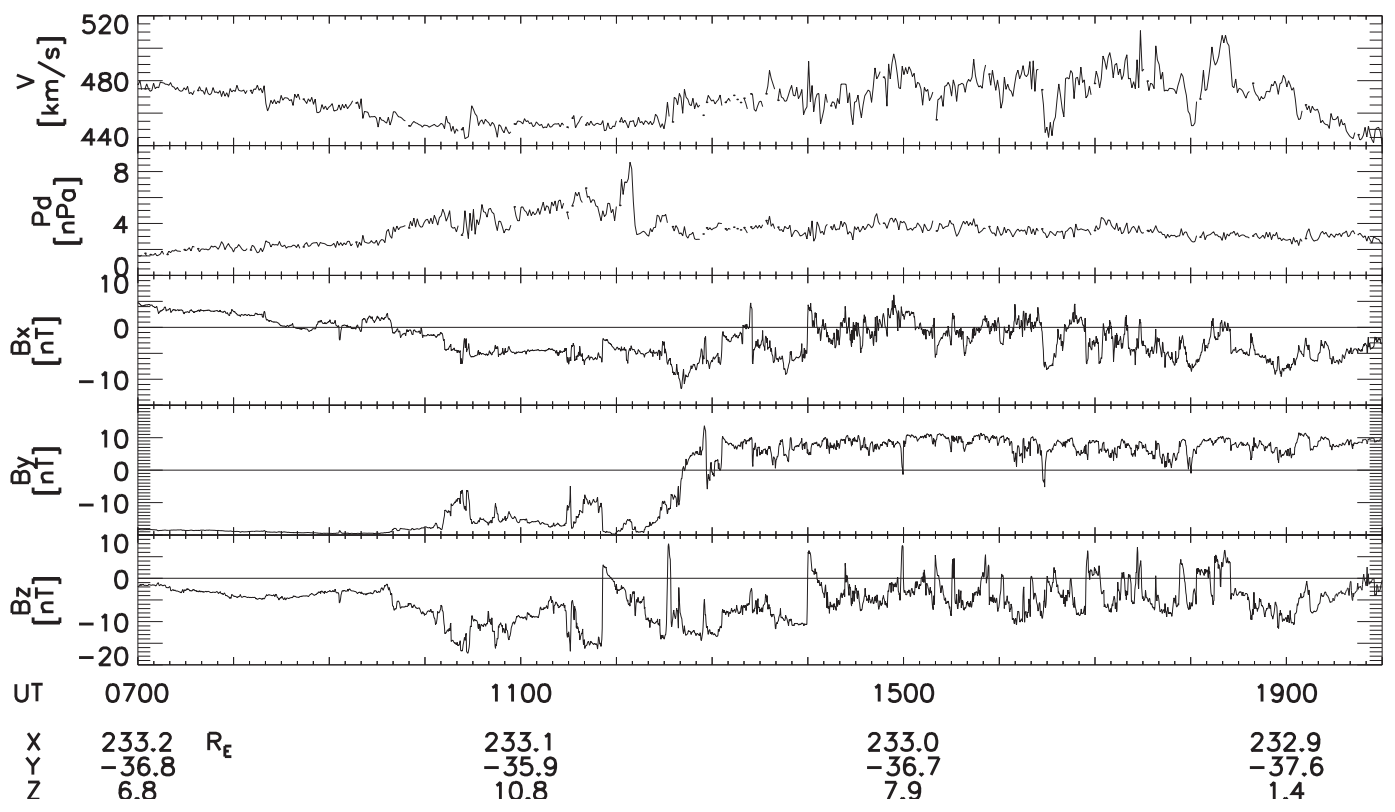

Fig. 2. Solar wind parameters obtained by ACE. The data are shifted by $50 \mathrm{~min}$ forward. From top to bottom, the solar wind speed, dynamic pressure, and three components of the magnetic field in the GSM coordinate system.

The LANL and GOES satellites are at geosynchronous orbit, and their coordinated (i.e., azimuthally distributed) observations provide a global picture at $6.6 R_{E}$. The LANL satellites acquire plasma data with electrostatic analysers (Bame et al., 1993), from which the magnetic field direction can be deduced (Thomsen et al., 1996), and also observe energetic particles with the Synchronous Orbit Particle Analyzer (SOPA, Belian et al., 1992). The GOES satellites measure the magnetic field.

In order to monitor the solar wind, we used the data obtained by the Solar Wind Electron, Proton, and Alpha Monitor (SWEPAM, McComas et al., 1998) and the Magnetometer instrument (MAG, Smith et al., 1998) onboard the ACE spacecraft. ACE was located about $233 R_{E}$ upstream of the Earth during the event studied here.

Auroral and magnetometer data were obtained from THEMIS Ground-Based Observatories (GBO, Mende et al., 2008; Russell et al., 2008). We also used magnetometer data from other stations (INTERMAGNET).

\subsection{Global context and ground observations}

Figure 1 shows the sawtooth event on 20 November 2007. Recurrent flux enhancements and gradual decreases at geosynchronous orbit were seen. The event occurred during the main phase of a moderate magnetic storm (with a minimum Sym- $H$ index of $\sim-65 \mathrm{nT}$, as shown in the bottom of Fig. 1). In the present study, we focus on a substorm event that corresponds to the first "tooth" of the sawtooth event (started at $\sim 09: 00 \mathrm{UT}$ ).
Figure 2 displays the solar wind parameters in the GSM coordinate system obtained by ACE. The data are shifted by $50 \mathrm{~min}$ forward in order to see their effects on the Earth's magnetosphere. The solar wind speed was moderate $(\sim 470 \mathrm{~km} / \mathrm{s})$ throughout the sawtooth event. Weak sudden change of the dynamic pressure was seen at $\sim 09: 35$ UT, but there was no significant change prior to the initiation of the first tooth $(\sim 09: 00 \mathrm{UT})$. Before the first tooth onset, the interplanetary magnetic field (IMF) $B_{z}$ was moderately negative $(\sim-5 \mathrm{nT})$, with a strongly negative $B_{y}(\sim-20 \mathrm{nT})$ and small $B_{x}(0-5 \mathrm{nT})$. After 09:35 UT, the strongly negative $B_{z}$ persisted until $\sim$ 15:00 UT, although several northward excursions were seen. The prolonged southward IMF period roughly corresponds to the duration of the sawtooth event.

Figure 3 demonstrates the auroral activity for this event. At 09:04:30 UT, weak brightenings were seen at KIAN and WHIT. Although not shown here, a keogram for KIAN shows a slight poleward expansion that subsided soon ( 09:05 UT). Since this activity was not followed by a largescale expansion, we regard it as a pseudobreakup (or pseudo onset; cf. Aikio et al., 1999, and references therein). From the auroral images, the major expansion onset time was determined to be $\sim 09: 07: 30 \mathrm{UT}$. A possible relation of the prior activity (i.e., what we call pseudobreakup) to the major onset is discussed later. As shown below, both of these two activities coincided with the magnetic bay appearances at ground stations. After the major onset, the breakup arc significantly expanded poleward, as observed at KIAN $(21.5 \mathrm{~h}$ MLT), FYKN (22.5 h MLT), INUV (23 h MLT), and WHIT (23 $\mathrm{h}$ MLT). On the other hand, the discrete arc was not clearly observed at GILL ( $2.5 \mathrm{~h}$ MLT). 

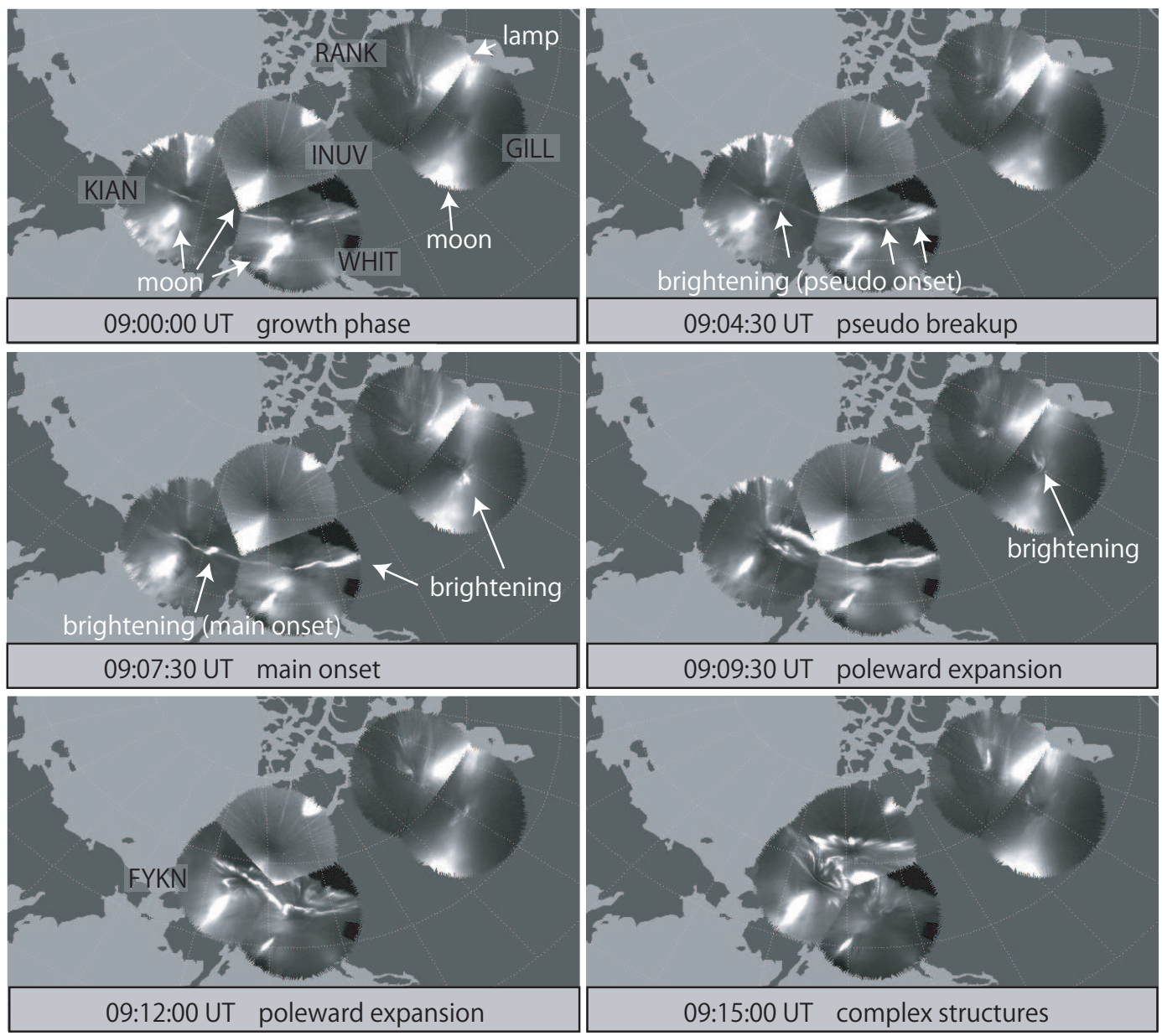

Fig. 3. Selected auroral images obtained by ground observatories. The time step is not constant. The pseudobreakup was seen at KIAN and WHIT at 09:04:30 UT, followed by the major onset at 09:07:30 UT and the subsequent poleward expansion. Some activities were also seen in the postmidnight sector. In the last two panels, the KIAN station is replaced by the FYKN station for better visibility.

Geomagnetic field variations observed at selected stations are shown in Fig. 4. The top and bottom panels are for stations at geomagnetic latitudes of $\geq 60^{\circ}$ and $<60^{\circ}$, respectively. Small negative (positive) bays at the higher (lower) latitudes first appeared at the pseudo onset ( 09:04:30 UT, the vertical solid line). The bays became much more significant after the major onset (09:07:30 UT, the vertical broken line) at all stations shown in the figure, although the initiations at most stations were delayed $\sim 1 \mathrm{~min}$ from the first signature at KIAN (21.5 h MLT) at 09:07:30 UT.

In order to illustrate the local time distribution of magnetic bays and its development, we plotted magnetic bays at low latitudes in Fig. 5. Data from ground stations (geomagnetic latitudes of $<60^{\circ}$ ) in the Northern Hemisphere were used, and latitudinal dependence of bay depths was corrected using the method of Sun et al. (1998). The upper and lower panels, respectively, show the deviations of the magnetic field $\mathrm{X}$ (or $\mathrm{H}$ ) and $\mathrm{Y}$ (or $\mathrm{D})$ components; the reference time is 09:04:30 UT. The bay distributions after the major onset (at
09:12:00 and 09:24:30 UT) are shown in Fig. 5a, and both illustrate the typical signature indicative of the SCW: the magnetic field X component peaked at the centre of the distribution with a gaussian-like shape, and the bipolar Y-component structure with positive values on the westward side. These are well explained by the pair of the downward and upward field-aligned currents (FACs) on the eastward and westward sides, respectively (McPherron et al., 1973). The positive bays were observed at $\sim 14-3 \mathrm{~h}$ MLT at 09:12 UT. We fitted the X-component distributions with Gaussian, and the full width at half maximum (FWHM) was determined to be $6.5 \mathrm{~h}$ in MLT. The SCW's relatively broad width compared to those in isolated substorms ( $\sim 4 \mathrm{~h}$ in MLT) is consistent with the previous results (Kitamura et al., 2005; Clauer et al., 2006). Furthermore, we note the significant eastward shift of the SCW, whose centre moved by $\sim 3 \mathrm{~h}$ in MLT in $\sim 10 \mathrm{~min}$. The width of the SCW slightly decreased (the FWHM was $6 \mathrm{~h}$ in MLT at 09:24:30 UT). 


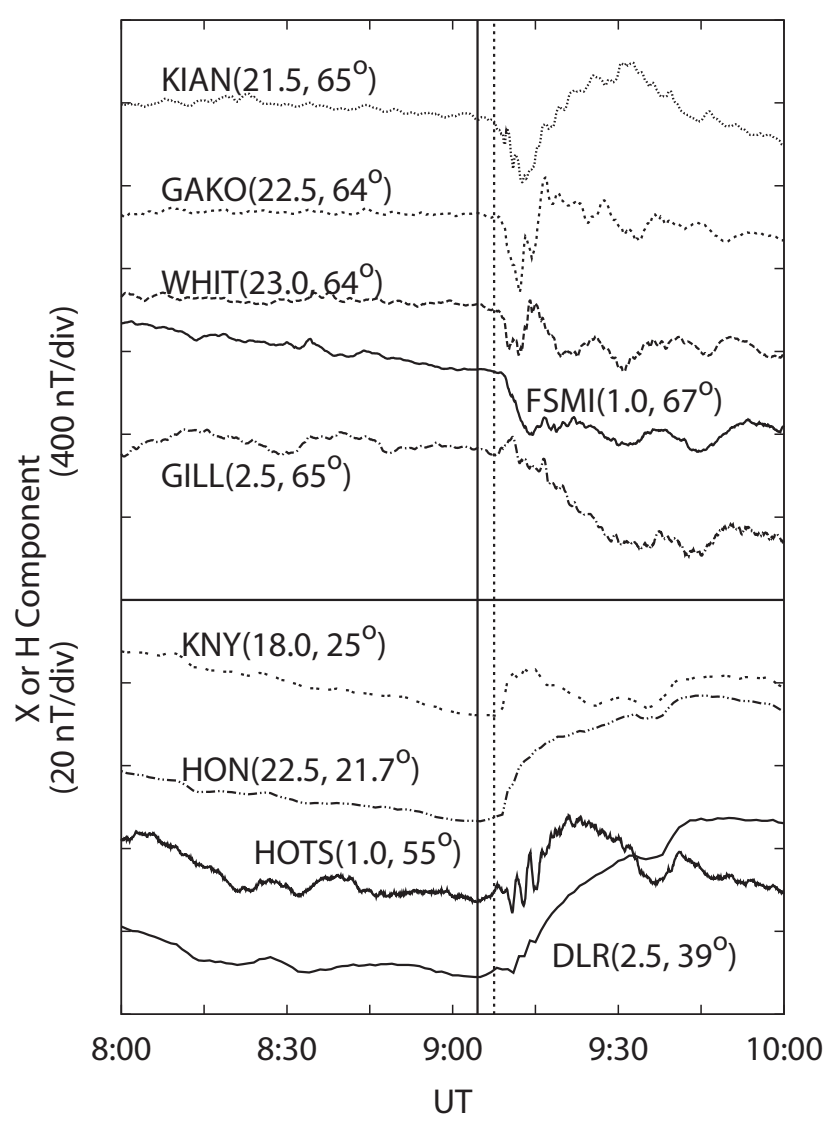

Fig. 4. Variations of the magnetic field $X$ or $H$ component observed at selected ground stations. The top panel is for the stations with geomagnetic latitudes (MLat) of $\geq 60^{\circ}$ ( $400 \mathrm{nT} / \mathrm{div}$ ), while the bottom is for the ones with the MLat $<60^{\circ}(20 \mathrm{nT} / \mathrm{div})$. The station codes, their MLT around 09:00 UT, and MLat are displayed. The solid and dotted vertical lines represent the approximate pseudo onset time (09:04:30 UT) and the major onset time (09:07:30 UT), respectively.

The bay distribution after the pseudobreakup (but prior to the major onset) is shown in Fig. 5b. Although the amplitude was small $(<1 \mathrm{nT})$, the pseudo onset bays show significant azimuthal extent, comparable to the major onset bay distribution. The east-west component distribution (the bottom panel) was roughly bipolar, while some fine structures were superposed in the premidnight sector.

Magnetic field Pi2 oscillations (period of 40-150s) are shown in Fig. 6. At the major onset (09:07:30 UT), the amplitudes suddenly and significantly. In a closer look, slight amplifications were also seen at the pseudo onset (09:04:30 UT). However, the earlier signatures were evident only in the dusk and premidnight sectors (i.e., at KNY, KIAN, GAKO, WHIT, and PINA). The absence in the other stations would be due to the smallness of this activity.

\subsection{Plasma flow, dipolarisation, and injections around geosynchronous orbit}

The satellite orbits in GSM coordinates during 08:00 to 10:00 UT are shown in Fig. 7. The LANL satellites were located in the postnoon (LANL-02A, L02 hereafter), dusk (LANL-97A, L97), midnight (1989-046, L89), and dawn (1994-084, L94) sectors. GOES-11 (G11) and GOES-12 (G12) were in the midnight and dawn sectors, respectively. THC was on outbound pass and in the postmidnight sector. THD and THE were in the dawn sector with a larger radial distance, and also outbound. The $x-z$ plane of Fig. 7 also illustrates the model magnetic field lines (Tsyganenko, 2002a, b) on the THC pass for 09:00, 09:10, and 09:20 UT, as a rough guide. An input parameter that is responsible for the model cross-tail current intensity was tuned for each time to reproduce the measured magnetic fields. In the right and bottom panels of Fig. 7, ion flows perpendicular to the background magnetic field are represented by arrows, every $10 \mathrm{~min}$ from 08:00 to 10:00 UT, and every $30 \mathrm{~s}$ for the period of bursty flows (09:00-09:14 UT, being smoothed by running averaging over $200 \mathrm{~s}$ ). Out of the bursty flow period, the durations after the major onset (09:07:30 UT) are displayed by the grey arrows. THD and THE observed flows at $>100 \mathrm{~km} / \mathrm{s}$ before 09:00 UT, while the flow speed became less after the major onset time (09:07:30 UT). The flow direction was predominantly sunward. On the other hand, duskward-dominant flows were observed by THC before the major expansion onset. After 09:07:30 UT, the flow vector rotated equatorward and earthward, suggestive of the satellite motion across a flow vortex (cf. Keiling et al., 2009).

Figure $8 \mathrm{a}-\mathrm{c}$ shows the ion flows perpendicular to the ambient magnetic field and the $\boldsymbol{E} \times \boldsymbol{B}$ drift velocities observed by THC. In order to obtain $E_{z}$ in the spacecraft frame (in the direction of the spin axis), we assumed $\boldsymbol{E} \times \boldsymbol{B}=0$. In these panels, it is seen that the ion flows were in rough agreement with the $\boldsymbol{E} \times \boldsymbol{B}$ drift before 09:13 UT. The large disagreement after 09:13 UT would have been caused by the contamination by energetic electrons. Penetrating particles and the bremsstrahlung process generate spurious signals in the whole energy range, resulting in the underestimation of the velocity. Ion flows at THD and THE were also consistent with the $\boldsymbol{E} \times \boldsymbol{B}$ drift, although not shown here.

Figure $8 \mathrm{~d}$ presents magnetic field variations at G11 $(\sim 0.5 \mathrm{~h} \mathrm{MLT})$, THC $(\sim 2.5 \mathrm{~h}$ MLT $)$, and G12 $(\sim 4.5 \mathrm{~h}$ MLT $)$, by plotting elevation angles $\left(\tan ^{-1}\left(B_{H} / \sqrt{B_{V}^{2}+B_{D}^{2}}\right)\right.$ and $\left.\tan ^{-1}\left(H_{p} / \sqrt{H_{e}^{2}+H_{n}^{2}}\right)\right)$ as a measure of dipolarisation. Here we used VDH coordinates for THEMIS; $H$ is antiparallel to the Earth's dipole axis (positive northward), $D$ denotes the azimuthal direction (positive eastward), and $V$ completes the orthogonal coordinates and is positive outward from the centre of the Earth. For the GOES magnetic field, we used the coordinates comprised of the northward $\left(H_{p}\right.$, perpendicular to the satellite orbit plane), the earthward $\left(H_{e}\right.$, normal 

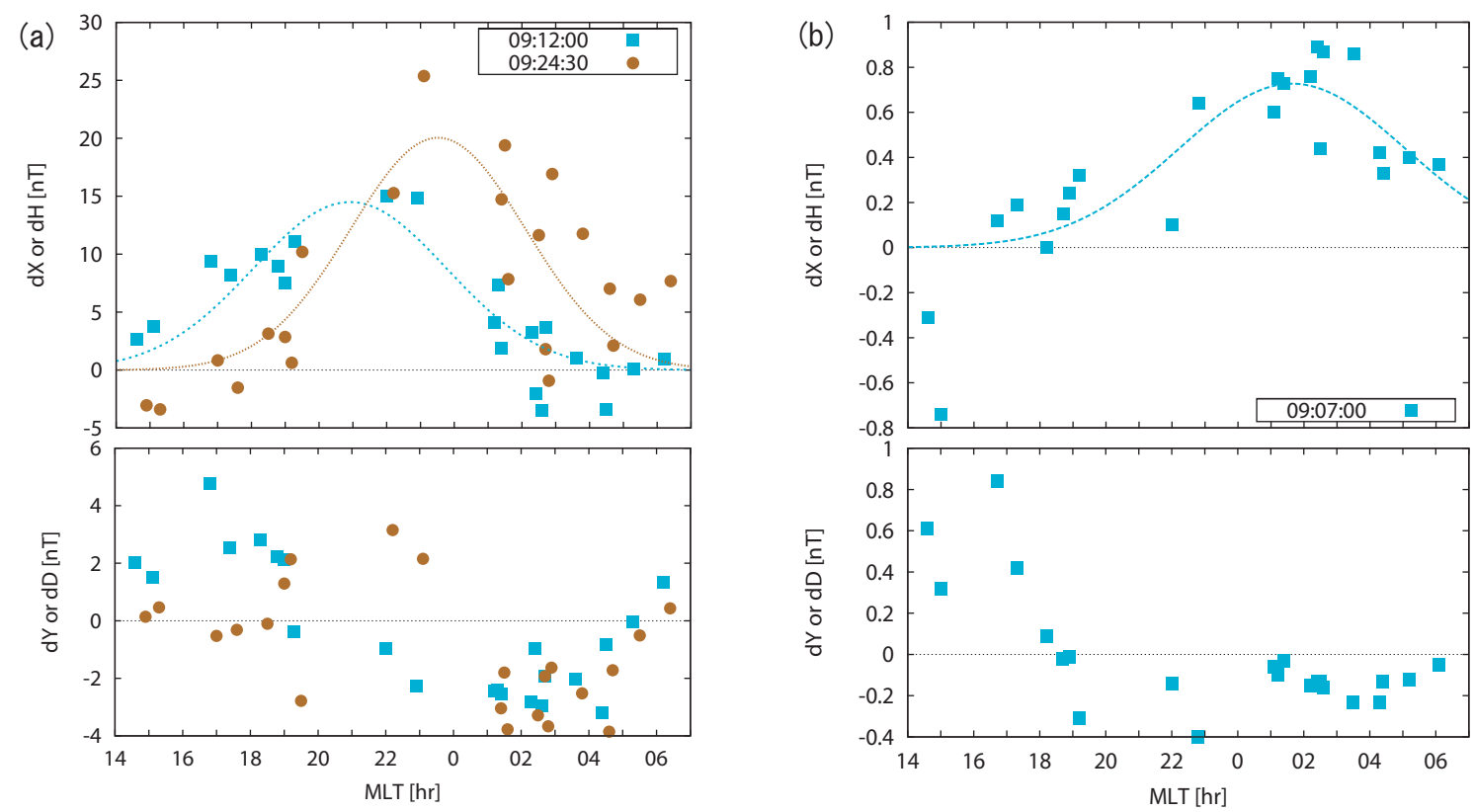

Fig. 5. Longitudinal distributions of the magnetic bays at low-latitude stations associated with (a) the major onset and (b) the pseudobreakup. The variations of the $\mathrm{H}$ or X components from 09:04:30 UT are shown in the top panel, while those of the D or Y components are in the bottom panel.

to $\left.H_{p}\right)$, and the eastward $\left(H_{n}\right.$, normal to $H_{p}$ and $H_{e}$ components). The elevation angle at THC was smaller than those at G11 and G12; this indicates the fact that THC was located rather northward of the magnetic equator, compared to G11 and G12. THC (2.5 h MLT) observed the initiation of dipolarisation almost simultaneously with the pseudo onset (at 09:04:30 UT). Similarly, G11 (0.5 h MLT) detected the initiation of magnetic field change at $\sim 09: 04: 30$ UT. Then, after 09:07:30 UT (the major onset time), an intermission of dipolarisation and a subsequent sporadic dips occurred, superposed on the gradual dipolarisation trend. G12 (4.5 h MLT) also detected a slight increase in the elevation angle around the major onset (the signature began earlier than the major onset).

Figure 8e shows the magnetic field elevation angle at L02 ( $\sim 14$ h MLT), L97 ( 19 h MLT), L89 ( $\sim 0$ h MLT), and L94 ( $\sim 6.5 \mathrm{~h} \mathrm{MLT})$, inferred from the low-energy plasma temperature anisotropy (cf. Thomsen et al., 1996): only reliable electron data are plotted (the criteria are: $T_{\|} / T_{\perp}<0.85$ or $>1.15$ and $0.93<T_{\perp} / T_{\mathrm{mid}}<1.07 ; T_{\|}=T_{1}, T_{\mathrm{mid}}=T_{2}$, and $T_{\perp}$ is the average of $T_{2}$ and $T_{3}$, where $T_{1}, T_{2}$, and $T_{3}$ are the three eigenvectors produced by the diagonalisation of the temperature matrix and $T_{1}$ is most different to other two values). L89 (0 h MLT) observed magnetic dipolarisation that started at 09:09 UT, while other LANL satellites did not observe any significant increase of the elevation angle around the onsets. The initiation was delayed from those at G11 and THC (09:04:30 UT), indicating that L89 was away from the ini- tial dipolarisation region that initiated around the pseudo onset. This absence of the dipolarisation in the midnight sector (at L89) and the presence in the postmidnight and dawn sectors is apparently inconsistent with the aurora that was more active in the dusk and premidnight sectors. This issue is discussed later (in Sect. 3.2). Due to the poor time resolution $(86 \mathrm{~s})$, the presence of the rapid magnetic field variations (e.g., dips, such as those observed by G11) was not examined for LANL data.

Figure $8 \mathrm{f}$ and $\mathrm{g}$ shows EPF variations for ions $(\sim 140 \mathrm{keV})$ and electrons $(\sim 130 \mathrm{keV})$, respectively, observed by the three LANL satellites and THC. Prior to the pseudo onset, L89 and L94 continued to observe the almost constant fluxes at levels of $\sim 150\left(\mathrm{~cm}^{2} \mathrm{sr} \mathrm{keV} \mathrm{s}\right)^{-1}$ for $\sim 140 \mathrm{keV}$ ions and $\sim 500\left(\mathrm{~cm}^{2} \mathrm{srkeV} \mathrm{s}\right)^{-1}$ for $\sim 130 \mathrm{keV}$ electrons. We call these reference values "pre-injection levels" of the above energy channels around nightside geosynchronous orbit, since the constant levels persisted for more than $1 \mathrm{~h}$ prior to the onset (see Fig. 1). L97 also observed the pre-injection levels before the gradual decrease due to the growth-phase plasma sheet thinning (see the flux level at $\sim 07: 00$ UT in Fig. 1). For ions, L02 (14 h MLT) detected a higher level, probably due to the observation at a different drift shell from other LANL satellites.

After the major onset, L89 (0 h MLT) observed ion and electron enhancements over the pre-injection levels. At the location of L97 (19h MLT), the ion flux enhanced over the pre-injection level, while the energetic electron flux 


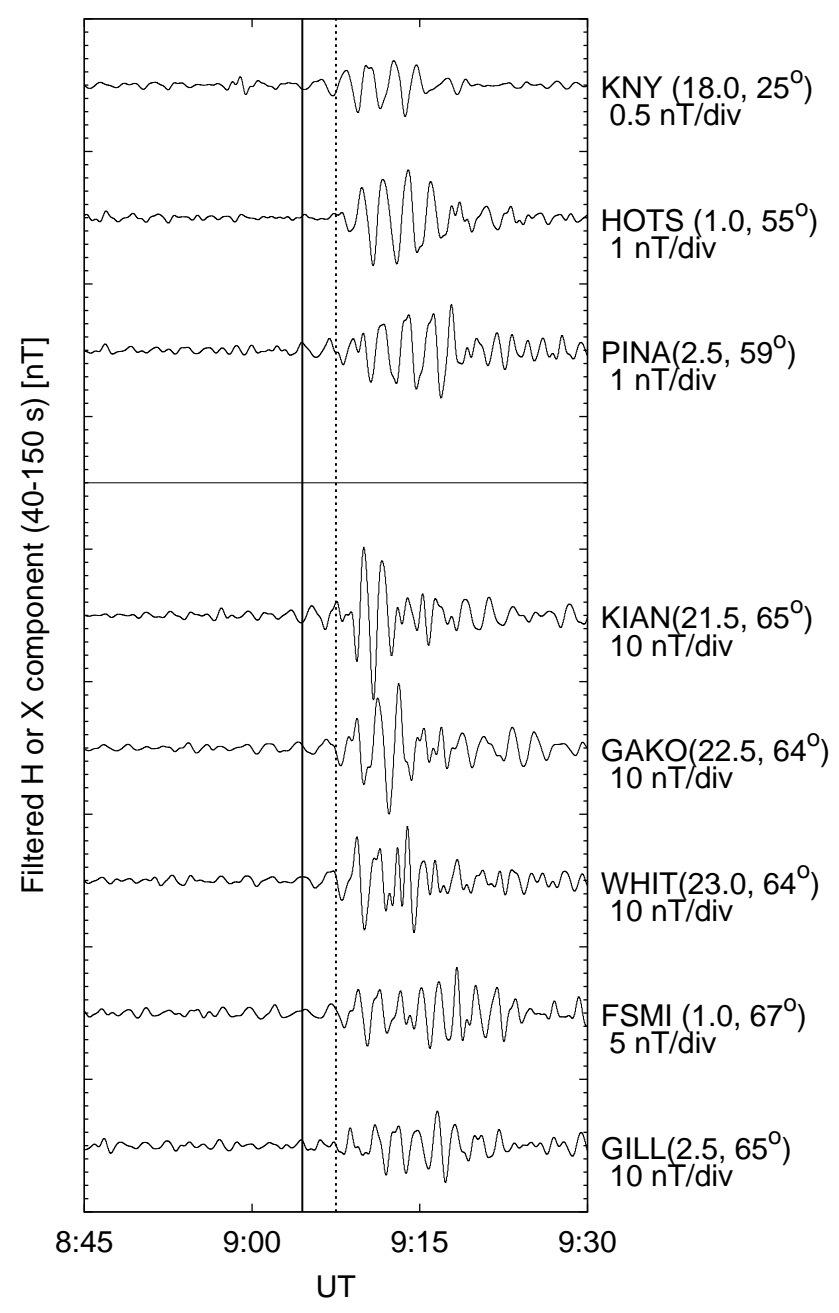

Fig. 6. Pi2 (40-150s) oscillations at selected ground stations. The station codes, their MLT around 09:00 UT, and MLat are shown. The solid and dotted vertical lines represent the approximate pseudo onset time (09:04:30 UT) and the major onset time (09:07:30 UT), respectively.

$(>100 \mathrm{keV})$ recovered to the pre-injection level without a significant net increase. L94 (6.5 h MLT) observed a gradual flux enhancement of electrons with energy dispersion (shown later). The ion and electron fluxes at THC (2.5 h MLT) started to increase around 09:04:30 UT and temporarily suspended with the intermission of the dipolarisation $(\sim 09: 08$ 09:10 UT, see Fig. 8d). After 09:10 UT, the energetic electron flux at THC significantly enhanced over the pre-injection level. The ion flux also rose slightly compared to the preinjection level.

Some of the energetic particle fluxes varied in two stages (Fig. 8f and g). The L97 ion flux first enhanced over the pre-injection level by 09:10 UT, and the second increase started at $\sim 09: 13$ UT. The L89 electron flux slightly dipped at $~ 09: 06$ UT, followed by the significant enhancement at $\sim 09: 11$ UT. These are likely to correspond to the two auro- ral activations at 09:04:30 UT and 09:07:30 UT; note that the geosynchronous injection time relative to the auroral breakup initiation is typically -2 to $+8 \mathrm{~min}$ (Liou et al., 2001). For other flux data, variations were small and/or complex and thus it is difficult to find clear correspondence with two auroral activities.

For the identification of energy-dispersive and dispersionless injections, we plot the energetic particle fluxes observed by LANL for various energy channels in Fig. 9. Vertical solid lines indicate the timing of the initiation of the significant flux increase at the highest energy channels shown here. It is seen that the flux recoveries and enhancements at L97 and L89 were dispersionless (both for ions and electrons), while enhancements at L02 and L94 were rather energy-dispersive. The second rise of L97 ion flux was overlapped by the first enhancement ( 09:13 UT).

In Fig. 10, we plot the variation of the energetic particle fluxes (blue for $\sim 140 \mathrm{keV}$ ions and green for $\sim 130 \mathrm{keV}$ electrons) after the injection (filled for 09:11:30 UT and open for 09:17:00 UT), in order to roughly show the azimuthal extent of the energetic particle injection regions. The values were normalised by the nightside pre-injection levels described above. Only for L02 (14h MLT), the flux at 08:00 UT was used as a reference value instead of the nightside pre-injection levels, since it observed a different preinjection level. The broadening of the azimuthal widths from 09:11:30 UT (filled) to 09:17:00 UT (open) was mainly due to the energetic particle azimuthal drift; it is strongly indicated by the energy dispersions shown in Fig. 9.

It should be noted that in Fig. 10 the flux variations of pseudo-onset origin and major-onset origin may have been mixed, due to the difficulty of clear separation. Nevertheless, Fig. 10 roughly shows the flux enhancement region during this substorm event.

\subsection{Particle signatures and dipolarisations observed by THEMIS}

Figure 11a shows magnetic elevation angles observed by THC (green), THD (red), and THE (blue). The elevation angle of THC is identical to that plotted in Fig. 8d. THD and THE also experienced the elevation increase in the same manner as THC did, despite their distance from the centre of the magnetic bays and the injection regions. The initiation was earlier at THD and THE ( 09:03 UT), while the variations were very similar. It should also be noted that the increase of the elevation angle started at THD and THE earlier than at G12 (4.5 h MLT geosynchronous altitude), suggesting that the dipolarisation propagated earthward.

Figure 11b displays the energy-time spectrograms for electrons obtained by THC. The energetic electron flux enhancement from $\sim 09: 11$ to 09:13 UT was dispersionless, while more significant increase was seen after 09:13 UT with considerable energy dispersion. This indicates that THC was 

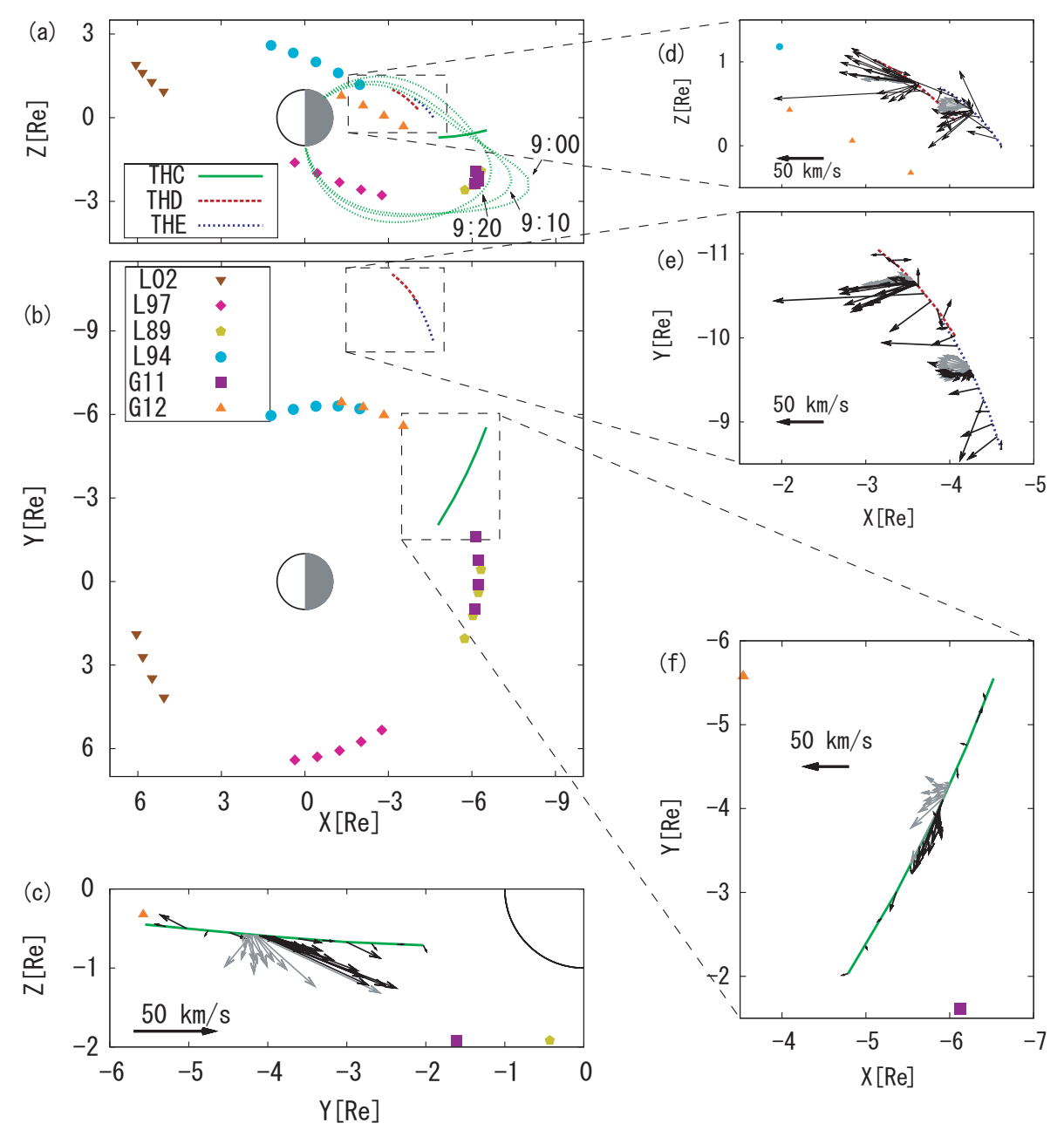

Fig. 7. (a) and (b) Orbits of the satellites in GSM coordinates from 08:00 UT to 10:00 UT on 20 November 2007. THEMIS-C, D, and E were outbound at the corresponding time. Green dotted lines in the panel (a) indicate the model field lines on which THEMIS-C was located at each time. Right and bottom panels (c), (d), (e), and (f) are enlargements of the THEMIS orbit, with ion flows (perpendicular to the magnetic field) shown by arrows.

inside the electron injection region, although the peak of the electron-enhanced region was rather westward.

After 09:15 UT, THD and THE also observed energetic electron injections with energy dispersion (Fig. 11c and d). The flux levels of the energetic electrons $(>30 \mathrm{keV})$ at THD and THE were much lower than those at THC. Similarly, the flux level was lower at THD than at THE. These facts indicate that the enhancement of the energetic electron flux is lesser at larger radial distances from the Earth (see also Fig. 7).

The outer radial limit of the energetic particle flux enhancement has been suggested observationally (e.g., Friedel et al., 1996) for non-sawtooth substorms. Furthermore, the similar location of the outer limit around $10-15 R_{E}$ from the Earth was well reproduced in substorm-injection simulations by Birn et al. (1997b, 1998). Therefore, it can be stated that the radial profile of the sawtooth-time injection is similar to non-sawtooth injections.

\subsection{Electromagnetic fields at THEMIS-C}

Let us now focus on the electromagnetic field variations observed by THC. The top panel of Fig. 12 shows the magnetic field data. The vertical solid and broken lines indicate the times of the pseudobreakup (09:04:30 UT) and the major onset (09:07:30 UT), respectively. Large-amplitude fluctuations in all three components of the electromagnetic field were prominent. It is important to note that these fluctuations started at $\sim 09: 01 \mathrm{UT}$; it is more than $3 \mathrm{~min}$ prior to the pseudobreakup (at 09:04:30 UT).

Another distinctive feature is the drastic change of the $B_{y}$ component after 09:04:30 UT. It provides important information on the FAC. The first pair of the increase 

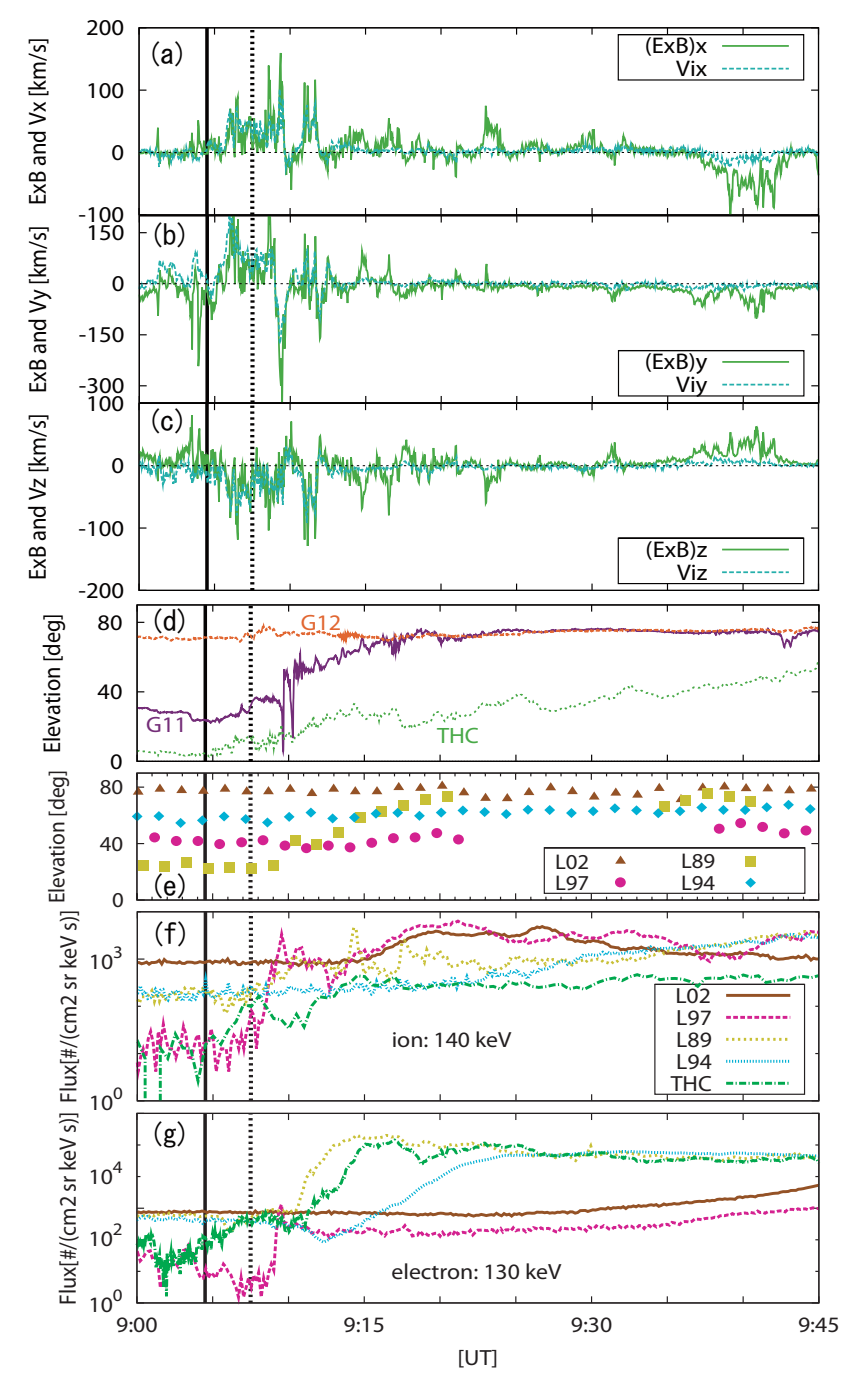

Fig. 8. (a-c) Three components of the $\boldsymbol{E} \times \boldsymbol{B}$ velocity and the ion velocity perpendicular to the ambient magnetic field. (d) Elevation angles of the magnetic field obtained by GOES and THC. (e) Elevation angles of the magnetic field obtained by LANL. (f) and (g) Energetic ion and electron fluxes. The times of the pseudo substorm onset (09:04:30 UT) and the major onset (09:07:30 UT) are indicated by the solid and dotted black lines, respectively.

(08:58-09:03 UT) and decrease (09:03-09:07:30 UT) of the $B_{y}$ is a signature of the typical FAC pair of the upward fieldaligned (R2) current and the downward field-aligned (R1) current (cf. Fujii et al., 1994). THC was moving outward (poleward) and thus first observed the R2 current (represented by the $B_{y}$ increase), which was located equatorward of the R1 current, and then observed the R1 current (represented by the $B_{y}$ decrease). A jump of the $B_{y}$ component at 09:07:30 UT indicates the enhancement of the downward current. The large-scale positive slope after the major onset 09:07:30 UT indicates the poleward motion of the cur-

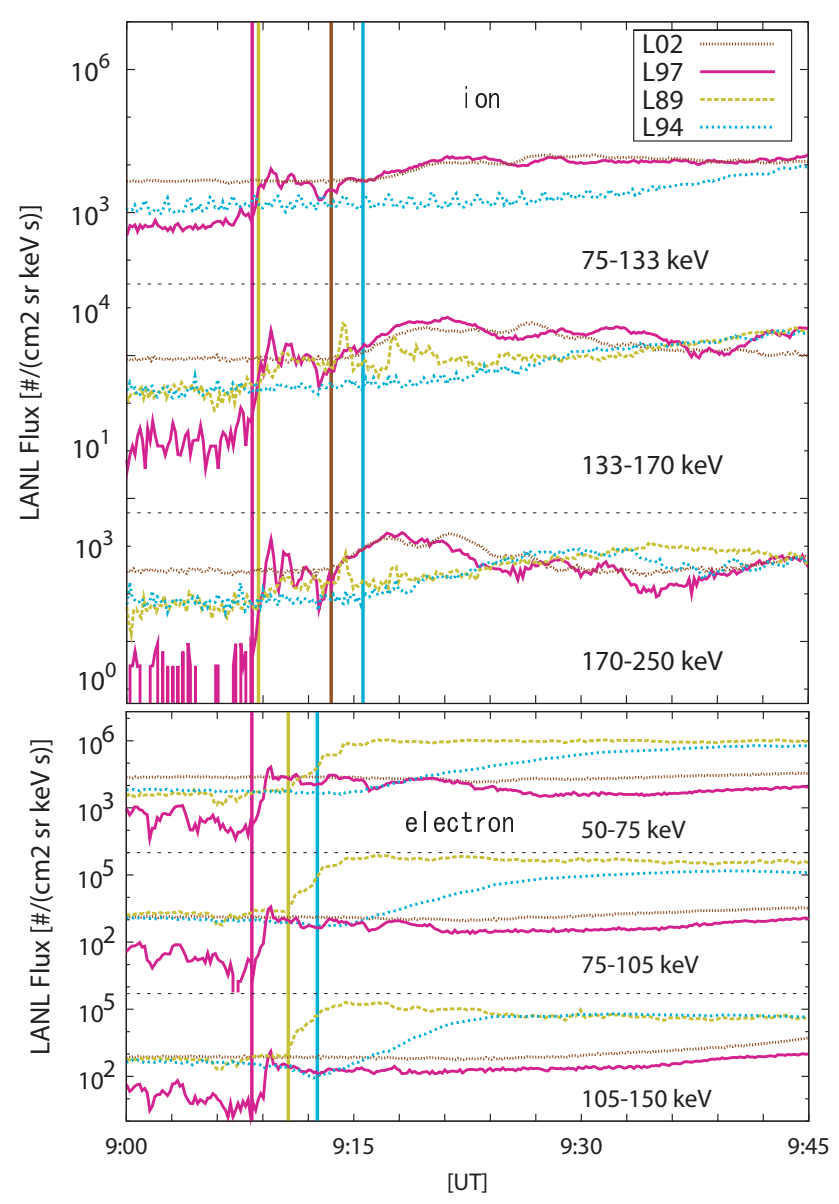

Fig. 9. Energetic particle fluxes with different energy channels observed by LANL satellites. Top three panels are for ions, and the bottom for electrons. Vertical solid lines indicate the timing of the flux increase initiation at the highest energy channels shown here. The L89 ion flux for 75-133 keV was not obtained for this period.

rent system associated with the plasma sheet expansion (i.e., the relative motion of the spacecraft was reversed to equatorward).

The electric field disturbance began before 09:04:30 UT (Fig. 12b), similar to the magnetic field. Large-amplitude fluctuations were seen, and one of the most prominent spikes of the $E_{z}$ component ( 09:09:30 UT) was coincident with the spike of the $B_{y}$ component, indicating its electromagnetic nature.

Pi2 range fluctuations of the electromagnetic fields and Poynting flux ( $S_{\|}$and $S_{\perp}$, for the components parallel and perpendicular, respectively, to the ambient magnetic field) are shown in Fig. 12c, d, and e (the pass band is 40-150 s). Some oscillations started to grow at $\sim 09: 01 \mathrm{UT}$, as mentioned above. Before 09:03 UT, however, the amplitudes were small, and the Poynting flux was negligible. After 09:03 UT (yet prior to the pseudobreakup), the Poynting flux became larger, and the parallel component was toward the 


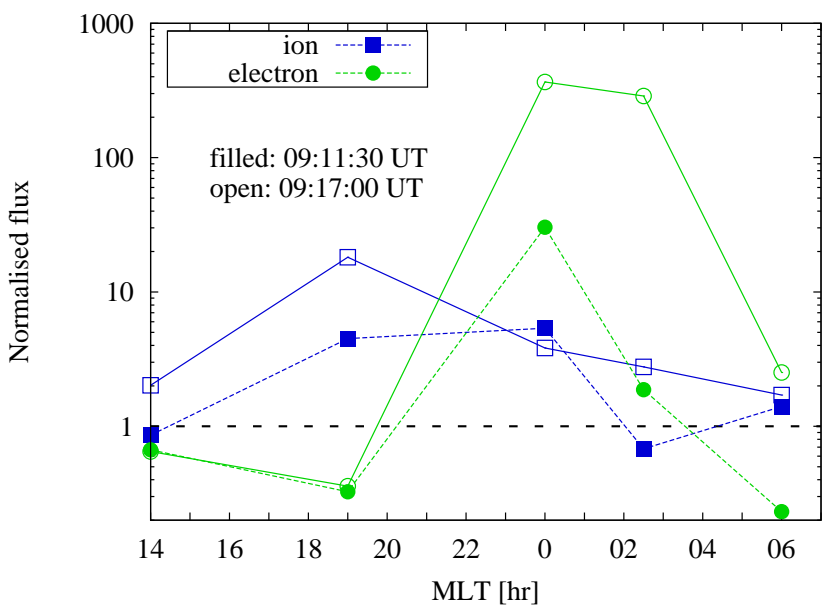

Fig. 10. Longitudinal distribution of the energetic particle flux normalised by the pre-injection levels. Ions of $\sim 140 \mathrm{keV}$ and electrons of $\sim 130 \mathrm{keV}$ are examined.

Earth (note that positive value means earthward). At around 09:04:30 UT, the peak value of the parallel Poynting flux $\left(\mathrm{S}_{\|}\right)$ was $\sim 0.01 \mathrm{~mW} / \mathrm{m}^{2}$. Since the magnetic field strength was $\sim 70 \mathrm{nT}$ and $\sim 56000 \mathrm{nT}$ at $\mathrm{THC}$ and the ionospheric mapping point, respectively, the observed flux is multiplied by 800 if we scale it along converging magnetic field lines to the ionosphere, and thus the Poynting flux becomes $8 \mathrm{~mW} / \mathrm{m}^{2}$ in the ionosphere.

More significant Poynting flux began at 09:08:30 UT. The peak was found at $\sim 09: 09: 30 \mathrm{UT}$; the value was $\sim 0.17 \mathrm{~mW} / \mathrm{m}^{2}$, and became $140 \mathrm{~mW} / \mathrm{m}^{2}$ when mapped to the ionosphere.

The E-to-B ratio of $\sim 0.8 \mathrm{mV} / \mathrm{m} / \mathrm{nT}$ corresponds to the velocity of $\sim 800 \mathrm{~km} / \mathrm{s}$. If this electromagnetic fluctuation is Alfvénic, this value should agree with the local Alfvén speed. Assuming that all ions are protons, the in situ Alfvén speed can be calculated with the magnitude of the magnetic field of $\sim 70 \mathrm{nT}$ and the density of $\sim 1 \mathrm{~cm}^{-3}$ to be $1400 \mathrm{~km} / \mathrm{s}$; it is much larger than the observed E-to-B ratio. However, it is well known that the near-Earth plasma sheet is oxygen-rich, especially for storm times. The observed E-to-B ratio agrees to the the Alfvén speed with 15\% oxygen ions (in the number density), and this content is typical during storm times (cf. Balsiger et al., 1980). Therefore, the large-amplitude electromagnetic fluctuation around 09:09:30 UT can be explained by Alfvén wave. In addition, we confirmed that the E-to-B ratio in the frequency domain increased with the frequency above $\sim 0.1 \mathrm{~Hz}$ (not shown here); this is a well known signature for kinetic Alfvén waves (e.g., Stasiewicz et al., 2001). On the other hand, the E-to-B ratio in the Pi2 range of $0.8 \mathrm{mV} / \mathrm{m} / \mathrm{nT}$ corresponds to the conductivity of $\sim 1 \mathrm{~S}$, which is rather small to be interpreted as the Pedersen conductivity around the eastern edge of the SCW (Gjerloev et al., 2000, and references therein). Therefore the observed electromag- netic fluctuation is not likely to be associated with the quasistatic field-aligned current, and this fact supports our conclusion that the fluctuation is Alfvénic.

It should also be noted that the Pi2 wave profile at GILL (2.5 h MLT) did not show similar amplification with that of the Alfvén wave at THC (started at 09:08:30 UT and ended at 09:10:30 UT). Thus, the correspondence between the observed Pi2-range waves in the magnetosphere and the ionosphere is unclear for this event. However, it is likely that the Alfvén wave observed by THC was launched at around the equator, since no negative (i.e., equatorward) Poynting flux was observed.

The presence of the slow-mode magnetosonic (MS) wave is also indicated by the anticorrelation between the ion pressure and the magnetic pressure (the bottom panel of Fig. 12). Here the ion pressure was calculated from the low-energy ion data obtained by the ESA; the energetic particle flux (SST data) was not included because of the lack of the complete calibration for moment calculation. However, judging from the preliminary data, contribution to the total ion pressure from the SST energy range does not substantively change the result. The slow-mode MS wave was initiated well before the pseudo onset time and continued over the displayed time period.

In summary, the large-amplitude electromagnetic field fluctuations in the perpendicular directions are well explained by the Alfvén wave, while the presence of the slowmode MS wave is also indicated.

\section{Discussion}

\subsection{Longitudinal extent of magnetic bays}

We illustrated the two magnetic bay developments; one is the weak signature at 09:04:30 UT (we call it pseudobreakup), and the other is the more salient signature after 09:07:30 UT (the major onset).

For the period after the major onset, we have shown the local time distribution of the magnetic north-south $(\mathrm{X}$ or $\mathrm{H})$ and east-west (Y or D) deviations in Fig. 5a. The single bump shape of the north-south deviations and the bipolar structure of the east-west components are in agreement with the SCW model (McPherron et al., 1973). The negative excursion of the north-south component at the edge of the Gaussian-like distribution is attributed to the fact that the station was eastward (westward) of the downward (upward) FACs. The wide distribution (FWHM $\sim 6.5 \mathrm{~h}$ in MLT) seen in this event is similar to the previous results (Kitamura et al., 2005; Clauer et al., 2006).

In addition to the wide distribution of the magnetic bays, we found the eastward shift of the distribution. Figure 5a shows that the centre of the SCW moved eastward by $\sim 3 \mathrm{~h}$ in MLT in about $10 \mathrm{~min}$, while the longitudinal extent became slightly narrower. This result contrasts with the conclusion of 
(a)
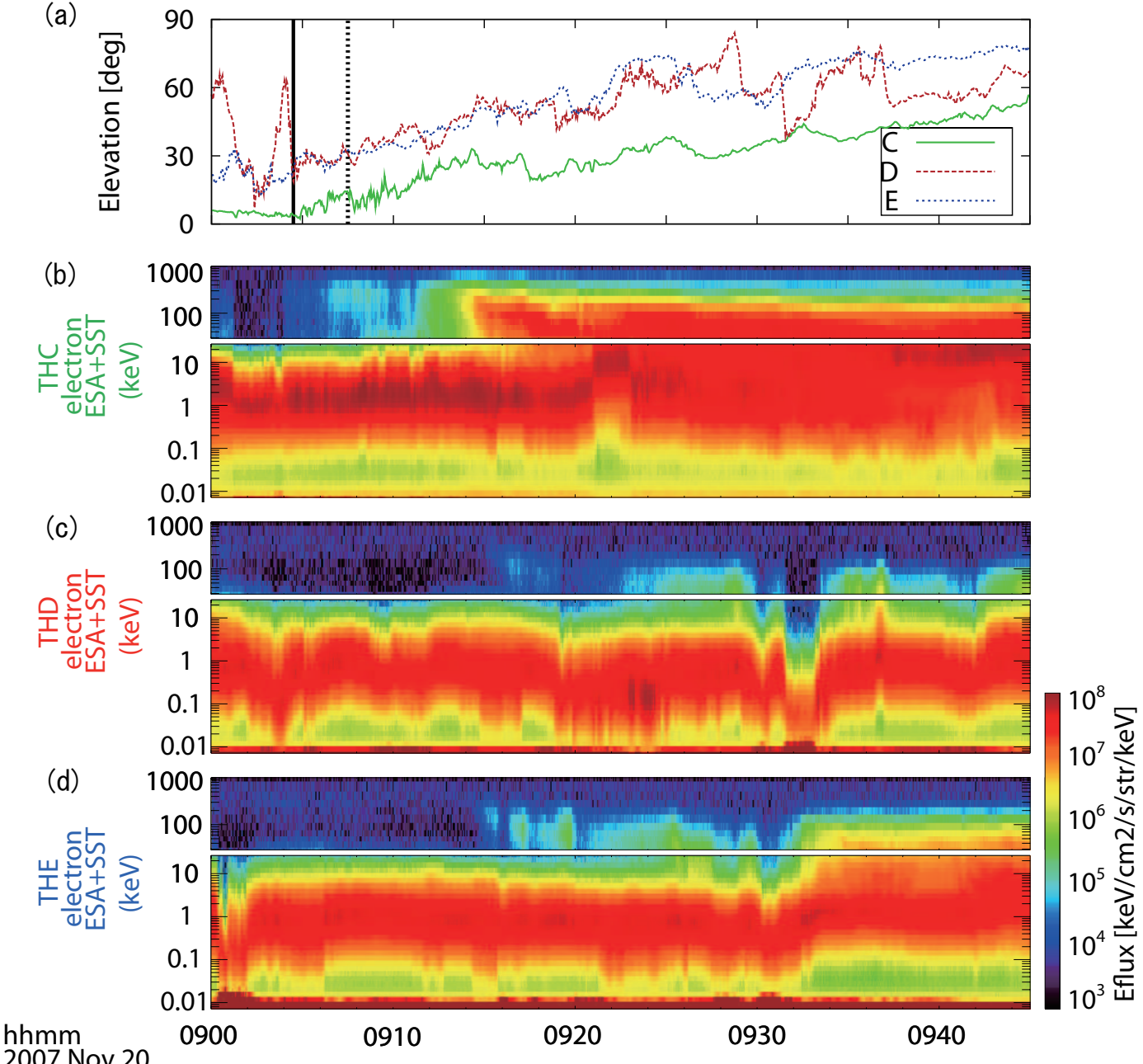

Fig. 11. (Top) Magnetic field elevation angles at THEMIS-C (green), D (red), and E (blue). (Bottom) The electron energy-time spectrograms obtained by SSTs and ESAs.

Kitamura et al. (2005); they examined six SCWs in the sawtooth event on 18 April 2002 and concluded that the peak of the SCW did not move for the time scale of tens of minutes. The present result is rather similar to the result of Henderson et al. (2006b). The apparent SCW eastward shift may correspond to the eastward shift of the plasma sheet activity and/or the topological change of the magnetic field.

A significant result here is the broad azimuthal extent of pseudobreakup magnetic bays. The pseudobreakup events often show small scale size (e.g., Ohtani et al., 1993; Nakamura et al., 1994). Although Koskinen et al. (1993) presented an event in which the ionospheric active region covered several hours of magnetic local time, it was still comparable to usual isolated substorms. In our event, however, the azimuthal extent of the pseudobreakup magnetic bay distribution was about twice as broad as those in usual substorms.
The downward FAC at $2.5 \mathrm{~h}$ MLT was observed by THC at the pseudo onset. This is consistent with the interpretation that the magnetic bays represent the large-scale SCW system.

\subsection{Spatial extent of dipolarisation}

G11 (0.5 h MLT), THC (2.5 h MLT), and G12 (4.5 h MLT) observed the initiation of magnetic field dipolarisations around the pseudobreakup (09:04:30 UT). THD and THE also observed magnetic elevation increases in the dawn sector $(\sim 4.5-5 \mathrm{~h} \mathrm{MLT})$ that started before the pseudobreakup. Following the major onset (09:07:30 UT), L89 (0 h MLT) finally observed the initiation of geosynchronous dipolarisation (with the delay of 1-2 min from the major onset). Dipolarisations at G11 (0.5 h MLT), THC (2.5 h MLT), G12 (4.5 h MLT), THE (4.5 h MLT) and THD (5 h MLT) also continued after the major onset. 
The dipolarisation from the midnight to the dawn sector started around the pseudobreakup (09:04:30 UT). It was well before the major expansion onset (09:07:30 UT) and the dipolarisation at the L89 location (0 $\mathrm{h}$ MLT).

The absence of the pseudo onset dipolarisation at L89 can be explained in terms of the radial distribution. It is likely that the midnight dipolarisation ( $0 \mathrm{~h}$ MLT) started slightly tailward of L89. This interpretation is consistent with the fact that a typical location of the dipolarisation initiation region is $X \sim-7 R_{E^{-}}-10 R_{E}$ (Miyashita et al., 2009). Almost the same discussion can be found in Ohtani et al. (1993), in which a significant dipolarisation was absent at geosynchronous orbit inside the SCW.

In summary, the dipolarisation region around the pseudo onset was observed between $\sim 0.5$ and $\sim 5 \mathrm{~h}$ MLT, and it engulfed the satellite at $0 \mathrm{~h}$ MLT after the major onset (09:07:30 UT). The western edge of the dipolarisation region after the major onset was eastward of $19 \mathrm{~h}$ MLT at geosynchronous altitude. The dipolarisation region was pronounced far outside geosynchronous orbit at least in the dawn sector, and the same is also suggested in the midnight sector.

\subsection{Spatial extents of the injection regions}

In Fig. 10, the discrepancy between the injection profiles of ions and electrons is clearly seen. Such a split structure was previously documented (Reeves et al., 1991; Birn et al. 1997a; Thomsen et al., 2001). The split can be attributed to the curvature/gradient (c/g) drift of energetic particles.

The dispersionless injections were observed at $19 \mathrm{~h}$ and $0 \mathrm{~h}$ MLT for ions, and at $0 \mathrm{~h}$ and $2.5 \mathrm{~h}$ MLT for electrons. The centre of these distributions roughly corresponds to the SCW centre. The location of the centre further supports the strong dipolarisation in the premidnight sector tailward of geosynchronous orbit, which was discussed in Sect. 3.2.

The outer limit of the injection region was indicated by the simultaneous measurements with THC, THD, and THE; the farther satellites away from the Earth observed the less enhancement of the energetic electron flux. This is similar to the suggestion by Friedel et al. (1996) and simulation result by Birn et al. (1998). Although their studies did not focus on sawtooth events, our result illustrates that their results can also be applied to sawtooth-time injections.

\subsection{Pseudobreakup during the Sawtooth event}

Magnetospheric and ionospheric activities following pseudobreakups (pseudo substorm onsets) are typically observed in a rather narrow longitudinal range, compared to those after usual substorm onsets (e.g., Ohtani et al., 1993; Nakamura et al., 1994). Although Koskinen et al. (1993) reported a pseudobreakup event that displayed the ionospheric activity extending over several hours of magnetic local time, the extent was still comparable to usual substorms. Similarly, in the study by Aikio et al. (1999), the longitudinal extents of pseudobreakup phenomena were comparable to usual substorms.

The present observations, however, demonstrate the widerthan-usual extent of dipolarisation and magnetic bays associated with a pseudobreakup; the widths were comparable to those during sawtooth-time substorms. Although the magnetic field Pi2 fluctuations at ground stations were weak and not clearly observed over the wide azimuthal range, magnetospheric electromagnetic disturbance was observed by THC (2.5 $\mathrm{h}$ MLT) around the pseudobreakup (09:04:30 UT) with a small earthward Poynting flux $\left(S_{\|} \sim 0.01 \mathrm{~mW} / \mathrm{m}^{2}\right)$. The initiation of the electromagnetic disturbance was $\sim 90 \mathrm{~s}$ prior to the pseudo onset, which is of the order of the Alfvén transit time. These results indicate that pseudobreakup events during sawtooth events can extend over broad longitudinal range, and suggest that the plasma sheet prior to the major onset is unstable over the wide azimuthal range during the sawtooth events, in comparison with usual substorms.

\subsection{Dawn-to-dusk electric field}

The earthward flows (i.e., the positive $v_{x}$ and $v_{y}$, and negative $v_{z}$ ) were observed by THC from $\sim$ 09:05 to $\sim 09: 09 \mathrm{UT}$, and they were due to the $\boldsymbol{E} \times \boldsymbol{B}$ drift for components perpendicular to the ambient magnetic field (Fig. 8a-c). However, the earthward $\boldsymbol{E} \times \boldsymbol{B}$ velocity was only comparable to the azimuthal velocity of the c/g-drifting $100 \mathrm{keV}$ particles in the dipole field at geosynchronous orbit $(\sim 50-70 \mathrm{~km} / \mathrm{s}$; cf. Hamlin et al., 1961), and the ratio of the $\boldsymbol{E} \times \boldsymbol{B}$ velocity to the c/g drift velocity is rather smaller in the stretched magnetic field (cf. Henderson et al., 2006b). Thus, it is not surprising that the ion flux at THC had little enhancement compared to the pre-injection level (Fig. 8f) and the significant electron flux enhancement at THC was brought only via the injection in the midnight sector (Fig. 8g), although the weak dispersionless injection was also seen (Fig. 11b).

On the other hand, significant dispersionless injections of energetic ions and electrons were observed by satellites in the dusk to midnight sectors. This difference from the postmidnight (the THC location) sector is attributed to the intensity of the dawn-to-dusk electric field; it is likely that the inductive electric field was much stronger near the centre of the injection region (the premidnight sector). However, it is difficult to address the relationship between the injection regions and the dawn-to-dusk electric field distribution, since there were no electric field measurements in the premidnight sector for the present event.

\subsection{Electromagnetic field fluctuation at THEMIS-C}

There are intense debates about whether sawtooth events consist of substorms or other magnetic disturbances. Lee et al. (2004) examined four sawtooth events and discussed that the observed signatures are unlikely to be those of substorms and rather they are directly driven by solar wind 
pressure increases. Lyons et al. (2005) also emphasised the importance of the dynamic pressure effect; they argued that the merging of the substorm component and pressure-driven component is essential for the wide azimuthal extents of the aurora and other signatures such as the current wedge. On the other hand, there are many studies concluding that sawtooth events are mainly composed of substorms with the wider substorm signatures (e.g., Huang et al., 2003b; Lui et al., 2004; Henderson et al., 2006a).

The present event is categorised as the latter, since no dynamic pressure increase was found in the solar wind around the onset, and the electromagnetic field fluctuations observed near geosynchronous orbit prior to and after the major onset (09:07:30 UT) were very similar to those reported as substorms in the literature. Maynard et al. (1996) studied six substorms with CRRES data $(5<L<7)$, and for all events they found the dusk-to-dawn excursions of the electric field prior to the substorm expansion onset. Such a signature was also seen in our event. The dawnward electric field (a few $\mathrm{mV} / \mathrm{m}$, similar to the result of Maynard et al.) was seen before 09:04:30 UT (Fig. 12).

Erickson et al. (2000) also noted similar eastward dips of the electric field $\sim 1-10$ min prior to the initiation of the SCW formation in other CRRES data sets. Furthermore, they showed the significant earthward Poynting fluxes that appeared just after the intensification of the magnetic bays. Also in the present event, such a signature was observed by THC (Fig. 12). The earthward Poynting flux suddenly enhanced at 09:08:30 UT. The peak value was capable of powering aurora $\left(140 \mathrm{~mW} / \mathrm{m}^{2}\right.$, mapped to the ionosphere). The large Poynting flux was Alfvénic, while the slow-mode MS waves were also seen.

The above authors argued that the initiation of dipolarisation and weak magnetic bays are prior activities that lead to the explosive onset, which is characterised by the intense earthward Poynting flux and more significant bays. From this point of view, the prior activity in our event, which we call pseudobreakup, can have significant relation with the major onset, rather than the independent activity. In fact, the observed initiation of dipolarisation and shallow magnetic bays during the prior activity (from 09:04:30 UT) are similar to those after the "local onset" in Erickson et al. (2000), followed by the explosive onset.

Maynard et al. (1996) and Erickson et al. (2000) showed electric field data predominantly near the substorm onset region in the premidnight sector. In fact, for isolated substorms, intense electric field disturbances are expected to be observed only near the onset region. For sawtooth-times, on the other hand, it is natural to expect electric field fluctuations to be observed azimuthally far from the centre of the SCW, since magnetic dipolarisations and the SCW show broad distributions in MLT. However, the electric field around geosynchronous orbit has not been extensively addressed due to the lack of the electric field instrument.
The THC observation in the present event showed the drastic electromagnetic fluctuations near the eastward edge of the broad SCW. The separation from the centre of the SCW was $\sim 5.5 \mathrm{~h}$ in MLT. This fact implies that inner-magnetospheric plasma sheet activity, such as the slow-mode MS wave and the large-amplitude Alfvén wave, are seen over a broad azimuthal range.

On the other hand, the radial distribution of such electromagnetic fluctuations during sawtooth events is still unknown. Lui et al. (2004) surveyed the behaviour of the magnetotail $\left(X<-20 R_{E}\right)$ during a sawtooth event, and found that there were some sawtooth activations that were not accompanied by any significant electromagnetic fluctuations in the plasma sheet. The result led the authors to the argument that the plasma sheet activity is localised even in the sawtooth event. Since the observation by Lui et al. (2004) was conducted more than $15 R_{E}$ tailward of geosynchronous orbit, future studies for the radial extent of the plasma sheet activity that cover $X \sim-10-15 R_{E}$ during sawtooth events are required.

\section{Summary}

We examined a sawtooth event with multiple spacecraft and the aid of ground stations. We restricted our analysis to the first "tooth" of the event, and our focus is on the spatial distributions of particle signatures and field variations, as well as fine structures and short time-scale signatures embedded in the sawtooth event.

From ground observations (auroral and magnetometer data), two activations were illustrated. The first magnetic bays and auroral brightening were observed at $\sim$ 09:04:30 UT, which we call pseudo onset (breakup). The second (deeper) magnetic bays and auroral breakup accompanied by the poleward expansion were initiated at 09:07:30 UT, which we regard as the major onset time.

The magnetic bays after the major onset showed the widerthan-usual azimuthal extent ( $\sim 14-3 \mathrm{~h}$ MLT) and the centre around $21 \mathrm{~h}$ MLT (later shifted to $0 \mathrm{~h}$ MLT). Furthermore, the magnetic bay distribution associated with the pseudo onset (or the prior activation) also extended over the wide magnetic local time range, although the magnitude was rather small. We also observed magnetic dipolarisations around the pseudo onset (09:04:30 UT) in the postmidnight and dawn sectors (between $0.5 \mathrm{~h}$ MLT and $5 \mathrm{~h}$ MLT). These observations indicate that the pseudobreakup activity (or it can be called prior activity) develops over a broad azimuthal range during sawtooth events. It suggests that during sawtooth events the plasma sheet prior to the major onset is unstable over a broad longitudinal range compared to isolated substorm cases.

The dipolarisation at geosynchronous orbit at $0 \mathrm{~h}$ MLT was observed only after the major onset, while dipolarisations in the postmidnight and dawn sectors continued. The absence 


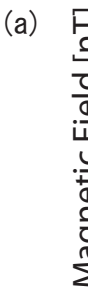

(b)
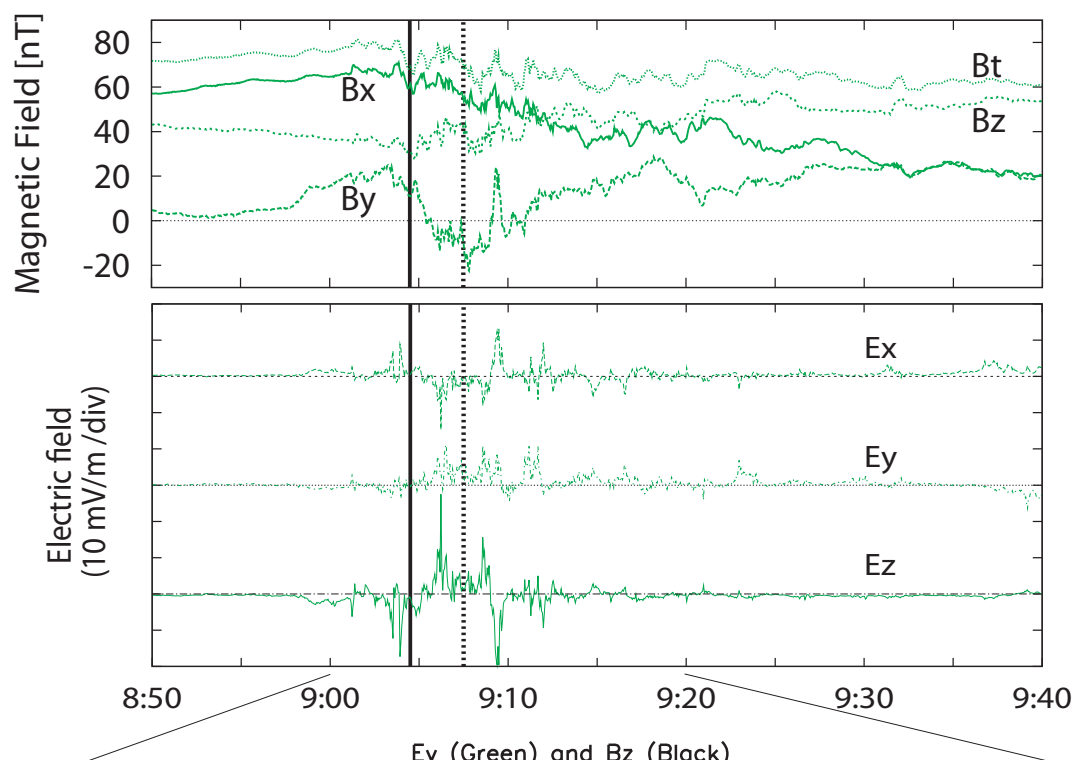

(c)
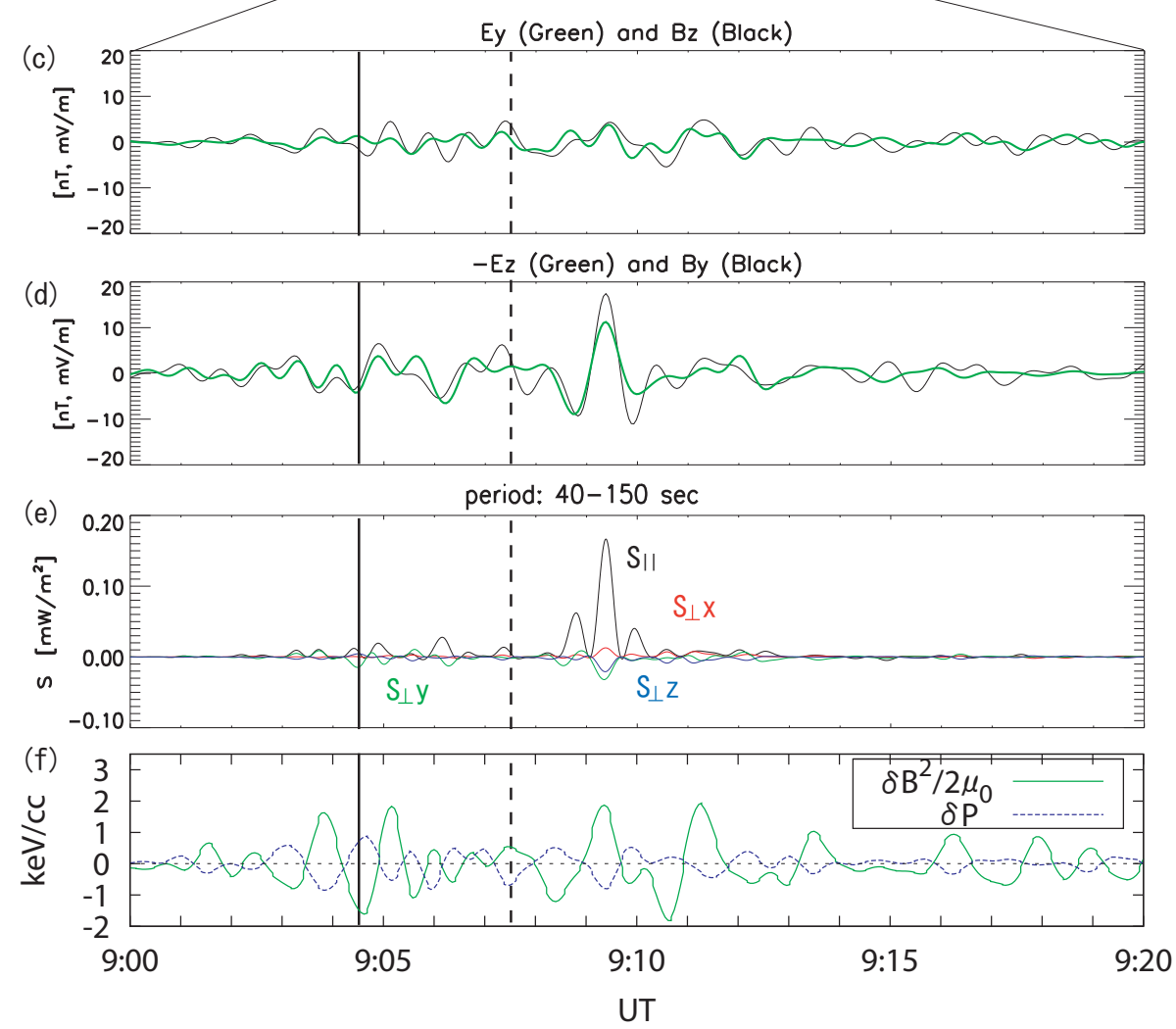

Fig. 12. (a), (b) Magnetic and electric field components measured by THEMIS-C, (c), (d), and (e) filtered (40-150 s range) fields and Poynting flux, and (f) the magnetic and plasma pressures. The pseudobreakup (09:04:30 UT) and the major onset (09:07:30 UT) are indicated by vertical lines.

of the dipolarisation at geosynchronous altitude before the major onset indicates that the inner radial limit of the dipolarisation region did not reach the geosynchronous satellite at the local midnight around the pseudo onset.
Injection regions of the energetic ions and electrons were displaced against each other; the dispersionless injection was observed at 19 and $0 \mathrm{~h}$ MLT for ions and at 0 and $2.5 \mathrm{~h}$ MLT for electrons. The conjunction measurements by THC, D, and $\mathrm{E}$ revealed that the outer limit of the electron injection 
region was located around $10 R_{E}$, which is similar to what is expected for non-sawtooth cases.

THC observed the electromagnetic field fluctuations and associated Poynting flux around the pseudobreakup and the major onset, despite its location $(\sim 5.5 \mathrm{~h}$ eastward of the SCW centre). The presence of slow-mode MS and Alfvén waves was identified; the earthward field-aligned Poynting flux $\left(140 \mathrm{~mW} / \mathrm{m}^{2}\right.$ when mapped to the ionosphere) of the Alfvén wave was seen after the major onset.

In this study, we could not address the azimuthal distribution of the equatorial electric fields especially around the centre of the injection regions, and thus further studies are required to acquire the overall picture of sawtooth events. Multipoint observations of field/particle instruments with other suitable alignments (e.g., another THEMIS satellite around premidnight geosynchronous region as well as more tailward regions), will unveil spatio-temporal relationships between fields and particles during sawtooth events more comprehensively.

Acknowledgements. The results presented in this paper rely on data collected at magnetic observatories. We thank the national institutes that support them and INTERMAGNET for promoting high standards of magnetic observatory practice (www.intermagnet.org). The authors also thank the THEMIS team, the LANL EP team, WDC, Kyoto, NICT, and NASA for the precious data. THEMIS was made possible and is supported in the US by NASA NAS502099. S. Kasahara is grateful to A. Prentice for carefully reading the manuscript. H. U. Auster was financially supported by the German Ministerium für Wirtschaft und Technologie and the German Zentrum für Luft- und Raumfahrt under grant 50QP0402. S. Kasahara was supported by a JSPS Research Fellowship for Young Scientists 19.1222.

Topical Editor I. A. Daglis thanks two anonymous referees for their help in evaluating this paper.

\section{References}

Aikio, A. T., Sergeev, V. A., Shukhtina, M. A., Vagina, L. I., Angelopoulos, V., and Reeves, G. D.: Characteristics of pseudobreakups and substorms observed in the ionosphere, at the geosynchronous orbit, and in the midtail, J. Geophys. Res., 104(A6), 12263-12287, 1999.

Angelopoulos, V.: The THEMIS Mission, Space Sci. Rev., 141, 534, 2008.

Auster, H. U., Glassmeier, K. H., Magnes, W., et al.: The THEMIS Fluxgate Magnetometer, Space Sci. Rev., 141, 235-264, 2008.

Balsiger, H., Eberhardt, P., Geiss, J., and Young, D. T.: Magnetic Storm Injection of 0.9- to 16-keV/e Solar and Terrestrial Ions Into the High-Altitude Magnetosphere, J. Geophys. Res., 85(A4), 1645-1662, 1980.

Bame, S. J., McComas, D. J., Thomsen, M. F., Barraclough, B. L., Elphic, R. C., Glore, J. P., Gosling, J. T., Chavez, J. C., Evans, E. P., and Wymer, F. J.: Magnetospheric plasma analyzer for spacecraft with constrained resources, Rev. Sci. Instrum., 64, 10261033, 1993.

Belian, R. D., Gisler, G. R., Cayton, T., and Christensen, R.: High $\mathrm{Z}$ energetic particles at geosynchronous orbit during the great solar proton event of October 1989, J. Geophys. Res., 97, 1689716906, 1992.

Belian, R. D., Cayton, T. E., and Reeves, G. D.: Quasi-periodic global substorm generated flux variations observed at geosynchronous orbit, in: Space Plasmas: Coupling Between Small and Medium Scale Processes, Geophys. Monogr. Ser., vol. 86, edited by: Ashour-Abdalla, M., Chang, T., and Dusenbery, P., pp. 143148, AGU, Washington, D.C., 1995.

Birn, J., Thomsen, M. F., Borovsky, J. E., Reeves, G. D., McComas, D. J., and Belian, R. D.: Characteristic plasma properties during dispersionless substorm injections at geosynchronous orbit, J. Geophys. Res., 102(A2), 2309-2324, 1997a.

Birn, J., Thomsen, M. F., Borovsky, J. E., Reeves, G. D., McComas, D. J., Belian, R. D., and Hesse, M.: Substorm ion injections: Geosynchronous observations and test particle orbits in threedimensional dynamic MHD fields, J. Geophys. Res., 102(A2), 2325-2341, 1997b.

Birn, J., Thomsen, M. F., Borovsky, J. E., Reeves, G. D., McComas, D. J., Belian, R. D., and Hesse, M.: Substorm electron injections: Geosynchronous observations and test particle simulations, J. Geophys. Res., 103(A5), 9235-9248, 1998.

Bonnell, J., Mozer, F. S., Delory, G. T., et al.: The THEMIS Electric Field Instrument, Space Sci. Rev., 141, 303-341, 2008.

Borovsky, J. E., Nemzek, R. J., and Belian, R. D.: The Occurrence Rate of Magnetospheric-Substorm Onsets: Random and Periodic Substorms, J. Geophys. Res., 98(A3), 3807-3813, 1993.

Cai, X., Henderson, M. G., and Clauer, C. R.: A statistical study of magnetic dipolarization for sawtooth events and isolated substorms at geosynchronous orbit with GOES data, Ann. Geophys., 24, 3481-3490, 2006,

http://www.ann-geophys.net/24/3481/2006/.

Clauer, C. R., Cai, X., Welling, D., DeJong, A., and Henderson, M. G.: Characterizing the 18 April 2002 storm-time sawtooth events using ground magnetic data, J. Geophys. Res., 111, A04S90, doi:10.1029/2005JA011099, 2006.

Erickson, G. M., Maynard, N. C., Burke, W. J., Wilson, G. R., and Heinemann, M. A.: Electromagnetics of substorm onsets in the near-geosynchronous plasma sheet, J. Geophys. Res., 105(A11), 25265-25290, 2000.

Friedel, R. H. W., Korth, A., and Kremser, G.: Substorm onsets observed by CRRES: Determination of energetic particle source regions, J. Geophys. Res., 101(A6), 13137-13154, 1996.

Fujii, R., Hoffman, R. A., Anderson, P. C., Craven, J. D., Sugiura, M., Frank, L. A., and Maynard, N. C.: Electrodynamic Parameters in the Nighttime Sector During Auroral Substorms, J. Geophys. Res., 99(A4), 6093-6112, 1994.

Gjerloev, J. W. and Hoffman, R. A.: Height-integrated conductivity in auroral substorms 1. Data, J. Geophys. Res., 105(A1), 215226, 2000.

Hamlin, D. A., Karplus, R., Vik, R. C., and Watson, K. M.: Mirror and Azimuthal Drift Frequencies for Geomagnetically Trapped Particles, J. Geophys. Res., 66(1), 1-4, 1961.

Henderson, M. G., Reeves, G. D., Skoug, R., Thomsen, M. F., Denton, M. H., Mende, S. B., Immel, T. J., Brandt, P. C., and Singer, H. J.: Magnetospheric and auroral activity during the 18 April 2002 sawtooth event, J. Geophys. Res., 111, A01S90, doi:10.1029/2005JA011111, 2006a.

Henderson, M. G., Skoug, R., Donovan, E., Thomsen, M. F., Reeves, G. D., Denton, M. H., Singer, H. J., McPherron, R. 
L., Mende, S. B., Immel, T. J., Sigwarth, J. B., and Frank, L. A.: Substorms during the 10-11 August 2000 sawtooth event, J. Geophys. Res., 111, A06206, doi:10.1029/2005JA011366, 2006b.

Huang, C.-S., Foster, J. C., Reeves, G. D., Le, G., Frey, H. U., Pollock, C. J., and Jahn, J. M.: Periodic magnetospheric substorms: Multiple space-based and ground-based instrumental observations, J. Geophys. Res., 108(A6), 1411, doi:10.1029/2003JA009992, 2003a.

Huang, C.-S., Reeves, G. D., Borovsky, J. E., Skoug, R. M., Pu, Z. Y., and Le, G.: Periodic magnetospheric substorms and their relationship with solar wind variations, J. Geophys. Res., 108(A6), 1255, doi:10.1029/2002JA009704, 2003 b.

Keiling, A., Angelopoulos, V., Runov, A., et al.: Substorm current wedge driven by plasma flow vortices: THEMIS observations, J. Geophys. Res., 114, A00C22, doi:10.1029/2009JA014114, 2009.

Kitamura, K., H. Kawano, Ohtani, S., Yoshikawa, A., and Yumoto, K.: Local time distribution of low and middle latitude ground magnetic disturbances at sawtooth injections of 18-19 April 2002, J. Geophys. Res., 110, A07208, doi:10.1029/2004JA010734, 2005.

Koskinen, H. E. J., Lopez, R. E., Pellinen, R. J., Pulkkinen, T. I., Baker, D. N., and Bosinger, T.: Pseudobreakup and substorm growth phase in the ionosphere and magnetosphere, J. Geophys. Res., 98(A4), 5801-5813, 1993.

Lee, D.-Y., Lyons, L. R., and Yumoto, K.: Sawtooth oscillations directly driven by solar wind dynamic pressure enhancements, J. Geophys. Res., 109, A04202, doi:10.1029/2003JA010246, 2004.

Liou, K., Meng, C.-I., Newell, P. T., Lui, A. T. Y., Reeves, G. D., and Belian, R. D.: Particle injections with auroral expansions, J. Geophys. Res., 106(A4), 5873-5881, 2001.

Lui, A. T. Y., Hori, T., Ohtani, S., Zhang, Y., Zhou, X. Y., Henderson, M. G., Mukai, T., Hayakawa, H., and Mende, S. B.: Magnetotail behavior during storm time "sawtooth injections", J. Geophys. Res., 109, A10215, doi:10.1029/2004JA010543, 2004.

Lyons, L. R., Lee, D. Y., Wang, C. P., and Mende, S. B.: Global auroral responses to abrupt solar wind changes: Dynamic pressure, substorm, and null events, J. Geophys. Res., 110(A9), A08208, doi:10.1029/2005JA011089, 2005.

Maynard, N. C., Burke, W. J., Basinska, E. M., Erickson, G. M., Hughes, W. J., Singer, H. J., Yahnin, A. G., Hardy, D. A., and Mozer, F. S.: Dynamics of the inner magnetosphere near times of substorm onsets, J. Geophys. Res., 101(A4), 7705-7736, 1996.

McComas, D. J., Bame, S. J., Barker, P., Feldman, W. C., Phillips, J. L., Riley, P., and Griffee, J. W.: Solar Wind Electron Proton Alpha Monitor (SWEPAM) for the Advanced Composition Explorer, Space Sci. Rev., 86, 563-612, 1998.

McFadden, J. P., Carlson, C. W. Larson, D., et al.: The THEMIS ESA electrostatic analyzer and in-flight calibration, Space Sci. Rev., 141, 277-302, doi:10.1007/s11214-008-9440-2, 2008.
McPherron, R. L., Russell, C. T., and Aubry, M. P.: Satellite studies of magnetospheric substorms on August 15, 1968. 9. Phenomenological model for substorms., J. Geophys. Res., 78, 3131-3149, 1973.

Mende, S. B., Harris, S. E., Frey, H. U., Angelopoulos, V., Russell, C. T., Donovan, E., Jackel, B., Greffen, M., and Peticolas, L. M.: The THEMIS Array of Ground-based Observatories for the Study of Auroral Substorms, Space Sci. Rev., 141, 357-387, doi:10:1007/s11214-008-9380-x, 2008.

Miyashita, Y., Machida, S., Kamide, Y., et al.: A state-of-the-art picture of substorm-associated evolution of the near-Earth magnetotail obtained from superposed epoch analysis, J. Geophys. Res., 114, A01211, doi:10.1029/2008JA013225, 2009.

Nakamura, R., Baker, D. N., Yamamoto, T., Belian, R. D., Bering III, E. A., Benbrook, J. R., and Theall, J. R.: Particle and Field Signatures During Pseudobreakup and Major Expansion Onset, J. Geophys. Res., 99(A1), 207-221, 1994.

Ohtani, S., Anderson, B. J., Sibeck, D. G., et al.: A Multisatellite Study of a Pseudo-Substorm Onset in the Near-Earth Magnetotail, J. Geophys. Res., 98(A11), 19355-19367, 1993.

Reeves, G. D., Belian, R. D., and Fritz, T.: Numerical tracing of energetic particle drifts, J. Geophys. Res., 96, 13997-14008, 1991.

Russell, C. T., Chi, P. J., Dearborn, D. J., Ge, Y. S., Kuo-Tiong, B., Means, J. D., Pierce, D. R., Rowe, K. M., and Snare, R. C.: THEMIS Ground-Based Magnetometers, Space Sci. Rev., 141, 389-412, 2008.

Smith, C. W., L'Heureux, J., Ness, N. F., Acuña, M. H., Burlaga, L. F., and Scheifele, J.: The ACE Magnetic Fields Experiment, Space Sci. Rev., 86, 612-632, 1998.

Stasiewicz, K., Seyler, C. E., Mozer, F. S., Gustafsson, G., Pickett, J., and Popielawska, B.: Magnetic bubbles and kinetic Alfven waves in the high-latitude magnetopause boundary, J. Geophys. Res., 106(A12), 29503-29514, 2001.

Sun, W., Shiokawa, K., Yumoto, K., Kitamura, T.-I., Olson, J. V., and Akasofu, S.-I.: The dependence of magnetic bays and the main phase of magnetic storms on magnetic latitude and local time, Mem. Fac. Sci., Kyushu Univ., 30, 71-80, 1998.

Thomsen, M. F., McComas, D. J., Reeves, G. D., and Weiss, L. A.: An observational test of the Tsyganenko (T89a) model of the magnetospheric field, J. Geophys. Res., 101(A11), 2482724836, 1996.

Thomsen, M. F., Birn, J., Borovsky, J. E., Morzinski, K., McComas, D. J., and Reeves, G. D.: Two-satellite observations of substorm injections at geosynchronous orbit, J. Geophys. Res., 106(A5), 8405-8416, 2001.

Tsyganenko, N. A.: A model of the near magnetosphere with a dawn-dusk asymmetry 1. Mathematical structure, J. Geophys. Res., 107(A8), 1179, doi:10.1029/2001JA000219, 2002a.

Tsyganenko, N. A.: A model of the near magnetosphere with a dawn-dusk asymmetry 2. Parameterization and fitting to observations, J. Geophys. Res., 107(A8), 1176, doi:10.1029/2001JA000220, 2002b. 